\title{
Educação e a crise estrutural do capital: o caso dos Estados Unidos*
}

John Bellamy Foster**

\section{Resumo}

O presente artigo argumenta que a decadência do ensino público é, nos Estados Unidos, principalmente, um produto de contradiçóes impostas externamente que são inerentes à educação na sociedade capitalista, agravadas em nossos tempos pelas condiçôes de estagnação econômicas, em especial nas economias desenvolvidas, e pelos efeitos do próprio movimento de reforma conservador. Para tal fim, apresenta os pressupostos da política educacional e os desdobramentos e consequências para a educaçáo pública - a partir de uma perspectiva histórica - no contexto da crise estrutural do capital nos Estados Unidos. Explicita-se a crise estrutural associada a uma nova fase do capitalismo: o capital monopolista-financeiro, caracterizada por: (1) estagnação econômica nas economias capitalistas desenvolvidas; (2) uma mudança dramática em direção à financeirização, as bolhas especulativas como meio de expansão econômica; e (3) a rápida concentração (e monopolização) de capital em uma escala global, mostrando, como uma consequência do lento crescimento endêmico para as economias desenvolvidas, que as grandes corporaçóes que dominam a economia mundial atual são obrigadas a procurar novos mercados para investimento, fora de suas áreas tradicionais de atuação, levando à aquisição e privatização de elementos-chave da administração do Estado. A contrapartida política do capital monopolista-financeiro é, portanto, a reestruturaçáo neoliberal, em que o Estado é cada vez mais ocupado por interesses privados. Apresentando diversos autores da área da economia e com base em Marx - o texto vai informando a relaçáo de degradação e desvalorização da educação pública. Finaliza suas análises indicando a necessidade de uma longa revoluçáo, para criar, entre outras coisas, uma nova educaçáo ligada à comunidade, e desenvolvida a partir das necessidades reais das pessoas.

Palavras-chave: Crise estrutural. Capital. Educação escolar pública. Estados Unidos da América

\footnotetext{
*Artigo publicado na Revista Monthly Review: an independent socialist magazine, v. 63, n. 3 jul./ aug. 2011, com o título Education and the structural crisis of capital the U.S. Case. Tradução de Claúdio Garcia Araújo. Disponível em: < http://monthlyreview.org/2011/07/01/educationand-the-structural-crisis-of-capital >. Este artigo é uma versão expandida do discurso de abertura da V Conferência Brasileira de Educação e Marxismo (EBEM), Universidade Federal de Santa Catarina, Florianópolis, Brasil, 11 de abril de 2011.

**Professor de sociologia na Universidade de Oregon. É editor da Monthly Review, e autor (com Fred Magdoff) de The Great Financial Crisis (Monthly Review Press, 2009)
} 
O atual movimento conservador pela reforma da educação pública nos Estados Unidos, e em grande parte do mundo, é baseado na opinião predominante de que a educaçấo pública encontra-se em um estado de emergência e na necessidade de sua reestruturação devido às próprias falhas internas. Em contraste, devo argumentar que a decadência do ensino público é, principalmente, um produto de contradiçôes impostas externamente que são inerentes à educação na sociedade capitalista, agravadas em nossos tempos pelas condiçôes de estagnação econômica nas economias capitalistas desenvolvidas e pelos efeitos do próprio movimento de reforma conservador. $\mathrm{O}$ ataque dirigido pelas corporaçôes aos alunos, professores e escolas públicas de ensino - simbolizada nos Estados Unidos pela legislação NCLB, No Child Left Behind (Nenhuma Criança Será Deixada Para Trás), de George W. Bush - deve ser explicada não tanto pelo fracasso das próprias escolas, mas pelos crescentes fracassos do sistema capitalista, que agora vê a privatização da educação pública como central para enfrentar seus problemas econômicos.

Vivemos em uma era de crise estrutural associada a uma nova fase do capitalismo: o capital monopolista-financeiro. Esta fase é caracterizada por: (1) estagnaçáo econômica nas economias capitalistas desenvolvidas; (2) uma mudança dramática em direção à financeirização, as bolhas especulativas como meio de expansão econômica; e (3) a rápida concentração (e monopolização) de capital em uma escala global ${ }^{1}$. Uma consequência do lento crescimento endêmico para as economias desenvolvidas é que as grandes corporaçóes que dominam a economia mundial atual são obrigadas a procurar novos mercados para investimento, fora de suas áreas tradicionais de atuação, levando à aquisiçấo e privatizaçáo de elementos-chave da administraçáo do Estado. A contrapartida política do capital monopolista-financeiro é, portanto, a reestruturaçáo neoliberal, em que o Estado é cada vez mais canibalizado por interesses privados.

Não é de surpreender que, sob essas circunstâncias, os círculos financeiros refiram-se à educação pública nos Estados Unidos, de maneira crescente, como uma oportunidade de mercado inexplorada - ou que o setor da educaçấo privada esteja demandando uma maior abertura do trilionário mercado global de educação pública para a acumulação de capital ${ }^{2}$. A educação, além disso, desempenha um papel crucial no desenvolvimento da força de trabalho, o que leva a crescentes apelos neoliberais para a sua reestruturação.

Assim, o estado de emergência da educação pública e a demanda por sua reestruturação e privatização devem ser compreendidos, fundamentalmente, 
como produtos do longo período de instabilidade econômica e social atual. A crise estrutural do capital como um todo se reflete na luta pela escolarização que, longe de ser incidental ao sistema nos dias de hoje, pode agora ser percebida como estando em seu núcleo ou próximo a ele. $\mathrm{O}$ resultado foi o ressurgimento da longa batalha por parte de grupos de interesses estabelecidos para instituir um sistema de ensino mercantilizado, levando a educação, cada vez mais, para os domínios do mercado. Atualmente, todos os meios são utilizados para alcançar esse fim, inclusive explorar as contradições de raça e de classe, a concorrência internacional e a própria instabilidade econômica

\section{A Política Econômica da Escolarização Capitalista}

Em meados dos anos 1970, os economistas radicais Samuel Bowles e Herbert Gintis criaram uma abordagem político-econômica útil para a análise do ensino fundamental e médio ${ }^{3}$ em seu trabalho pioneiro, Schooling in Capitalist America (BOWLES; GINTIS, 1976). Embora inicialmente tenha sido influente nos círculos de esquerda, Schooling in Capitalist America perdeu força entre os radicais na década de 1980 por se considerado muito determinista e economicista - não levando em consideração a complexidade cultural envolta na negociação de estudantes e educadores com o sistema ${ }^{4}$. Outros representantes da esquerda criticaram o argumento de Bowles e Gintis por ser demasiadamente "funcionalista" e não-dialético em sua análise ${ }^{5}$. No entanto, acredito que Schooling in Capitalist America constitui um ponto de partida útil para abordar a economia política da educaçâo capitalista, como esta se apresenta na era neoliberal.

Para Bowles e Gintis, a escolarização sob o capitalismo - se não combatida por poderosos movimentos democráticos de resistência - tende a evoluir em direção aos imperativos da classe capitalista, que a subordina às necessidades de produção e de acumulação. Isto é evidente no que os autores chamaram $o$ princípio de correspondência, ou a noção de que as "relaçôes sociais de educação", normalmente, correspondem às relaçóes sociais de produção na sociedade capitalista ${ }^{6}$. A escolarização, portanto, destina-se a servir a produção e reproduz a divisão hierárquica do trabalho desse sistema produtivo ${ }^{7}$. Assim, o propósito dominante da escolarização fundamental e média na sociedade capitalista - a formação de trabalhadores ou de força de trabalho para a produção - e o processo de trabalho interno à própria escolarização, da maneira como é realizado pelos 
trabalhadores da educação, são fundamentalmente condicionados pelas relações de produção econômicas que as envolvem.

Nesta perspectiva, as formas de consciência e comportamento promovidas pela escolarização capitalista são projetadas para reproduzir classes e grupos existentes e, portanto, destinam-se a reforçar e legitimar as relaçôes sociais de produção da sociedade capitalista como um todo. Os estudantes da classe trabalhadora e aqueles que são compelidos a trabalhar em ocupações típicas da classe trabalhadora são ensinados a seguir regras, enquanto estudantes provenientes da classe média alta e/ou talhados para o estrato profissionalgerencial são ensinados a internalizar os valores da sociedade (aqueles que encontram-se entre estes dois grupos, além de aprender a seguir regras, são principalmente treinados para serem confiáveis) ${ }^{8}$.

Pouco do que encontramos na escolarização nos níveis fundamental e médio é voltado para o desenvolvimento de habilidades efetivas e menos ainda para o desenvolvimento de conhecimento - que, à medida em que tornamse necessários, poderão ser obtidos no trabalho ou no ensino "pós-médio" (institutos e faculdades de formação profissional). Desse modo, as escolas dizem menos respeito à educação que a um tipo de modificação comportamental, preparando a grande maioria dos estudantes para uma vida de rotinizaçáo e padronização, em que quase todos irão acabar empregados em trabalhos que, essencialmente, não exigem qualificação e não oferecem possibilidades de crescer profissionalmente. $\mathrm{Na}$ verdade, a maioria dos empregos existentes no ambiente de trabalho degradado da sociedade capitalista monopolista - mesmo aqueles reservados para pessoas com curso superior - requerem quase nenhuma educação formal.

A educação fundamental e média de mais alta qualidade nos Estados Unidos, entretanto, encontra-se fora das escolas públicas, concentrada em um número muito pequeno das melhores escolas privadas, dedicadas ao ensino dos filhos dos muito ricos, cujo objetivo é gerar uma classe governante. Uma escola preparatória como a Phillips Academy em Andover, Massachusetts (incluindo ex-alunos como George H.W. Bush e George W. Bush) custa 32.000 dólares por ano, não incluindo custos de hospedagem e alimentação. Ela tem uma relação professor-aluno de 5 para 1, com 73 por cento dos professores pós-graduados, e um extenso currículo. Essas escolas são vistas como portas de entrada para a Ivy League9 (BARAN; SWEEZY, 1966).

Dessa maneira, o sistema educacional pode ser compreendido como 
correspondente, de várias maneiras, ao aumento da desigualdade, alienação e gradação/degradação do trabalho advindos do sistema de produção. Este argumento, tal como desenvolvido em Schooling in Capitalist America, não tinha como objetivo ser determinista, mas sim levantar questóes de luta de classes. "O quanto o sistema educacional [capitalista] consegue realmente alcançar seus objetivos", observaram Bowles e Gintis (1976, p. 129), "[...] varia de um período para o outro [....]. Na maioria dos períodos [...] os esforços para usar as escolas com o intuito de reproduzir e ampliar as relaçóes de produçáo capitalistas foram combatidos tanto pela dinâmica interna do sistema educacional como pela oposiçấo popular".

A parte histórica de seu livro discute extensamente sobre a dinâmica interna do sistema educacional - ou seja, as lutas, principalmente de professores, para conservar a autonomia dentro do sistema em prol da educaçáo das crianças - e sobre os movimentos populares que, periodicamente, surgiram em oposiçáo à principal tendência da educaçáo capitalista, na forma de movimentos contrahegemônicos de educadores, pais e membros da comunidade. No entanto, ambas as formas de luta tenderam a ser meras açóes de retaguarda (ou, na melhor das hipóteses, guerras de posição), quase nunca tomando a forma de assaltos violentos (guerras de movimento) sobre os princípios básicos da escolarização capitalista. $\mathrm{O}$ resultado foi o domínio total por parte da agenda corporativa.

\section{Capital Monopolista e a Ascensão do Modelo Corporativo de Escolarização}

A importância de uma ampla abordagem político-econômica sobre a educação pública como essa é que ela nos permite perceber a lógica subjacente que rege o desenvolvimento da escolarizaçáo capitalista nos Estados Unidos e em outros lugares. A educação pública surgiu nos Estados Unidos no início do século XIX. Mas o sistema educacional como o conhecemos hoje só surgiu, a partir de fins do século XIX e início do século XX. Seu desenvolvimento moderno corresponde, assim, ao surgimento do capitalismo monopolista, uma economia dominada por grandes corporaçóes. Estima-se que "entre um quarto e um terço" de todo o capital social americano investido na produçáo consolidouse por meio de fusóes e aquisiçóes entre 1898 e 1902. Na maior delas, a formação da U.S. Steel em 1901, em torno de 170 empresas foram reunidas em um único ano para criar a primeira corporaçáo bilionária, controlando 65 por cento da 
indústria siderúrgica. Isso representou a grande era da concentração corporativa, marcando o surgimento do capitalismo corporativo ${ }^{10}$.

Um elemento-chave na evolução e na estabilização desta nova etapa de acumulação, reside na oportunidade por ela criada para o que Marx chamou de "a subsunção real", em oposição à "subsunção formal do trabalho ao capital" (MARX, 1976, p. 1023-1025). No capitalismo do século XIX, os trabalhadores estavam em posição de reter para si mesmos o conhecimento de como o trabalho era realizado e, portanto, exerciam um considerável grau de controle sobre o processo de trabalho. Deste modo, o controle do processo de trabalho pelos proprietários e gerentes era, frequentemente, mais formal que real. Entretanto, conforme as corporaçóes e suas forças de trabalho e fábricas ficavam maiores com a ascensão do capitalismo monopolista, tornou-se possível estender a divisão do trabalho e, consequentemente, exercer maior controle administrativo de cima para baixo. Isto tomou a forma do novo sistema de administração científica, ou "Taylorismo", dentro da indústria concentrada. O controle da concepçáo do processo de trabalho foi sistematicamente removido dos trabalhadores e monopolizado pela administração. Daí em diante, de acordo com esta lógica administrativa, os trabalhadores serviam apenas para executar comandos vindos de cima, com cada um de seus movimentos controlados até o mais ínfimo detalhe ${ }^{11}$.

O principal resultado da introdução da administração científica na indústria, como Harry Braverman (1998) explicou em 1974 em Labor and Monopoly Capital, foi a degradação das condições de trabalho para a maioria dos trabalhadores. Cada vez mais, a sociedade capitalista monopolista era caracterizada por uma polarização da qualificação, com apenas uma limitada demanda por um número relativamente pequeno de trabalhadores altamente qualificados, em comparação com as massas de trabalhadores não qualificados. $\mathrm{O}$ sistema de educação projetado pelas corporaçôes foi construído com o objetivo de produzir trabalhadores adequados a cada um desses diferentes segmentos do mercado de trabalho. Mas a administração científica foi também vista como uma forma de dirigir o processo de trabalho dentro das próprias escolas submetendo os professores a novas formas de gestão corporativa.

A administração científica tornou-se um conceito amplamente conhecido nos Estados Unidos depois que Louis Brandeis, argumentando perante a Interstate Commerce Commission (Comissão de Comércio Interestadual), em 1910, exaltou publicamente a magia dos engenheiros da eficiência em aumentar 
os lucros corporativos. Isto foi seguido, em 1911, pela publicação de Principles ofScientific Management (Princípios de Administração Científica) de Frederick Winslow Taylor, inicialmente, como fascículos na American Magazine. A administraçáo científica e os experts em eficiência logo tornaram-se a febre entre os executivos e os funcionários públicos, rapidamente se espalhando para a administração de escolas públicas, onde padróes, testagem e escolas taylorizadas tornaram-se os princípios definidores de uma nova utopia: o modelo corporativo de sistema escolar. Assim, o especialista em eficiência Harrington Emerson fez um discurso para a High School Teachers Association of New York (Associação de Professores do Ensino Médio de Nova York), em 1911, que intitulou como Scientific Management and High School Efficiency (Administração Científica e Eficiência do Ensino Médio). Os últimos sete de seus doze princípios eram: registros padronizados, planejamento, condiçóes padronizadas, operaçóes padronizadas, instruçóes padronizadas, horários padronizados e recompensa por eficiência (CALLAHAN, 1962). Em 1913, Franklin Bobbitt, um especialista em administração educacional da Universidade de Chicago, escreveu na Supervision of City Schools:

O trabalhador deve constantemente receber instruçōes detalhadas quanto ao trabalho a ser feito, aos padróes a serem alcançados, aos métodos a serem empregados, e aos aparelhos a serem utilizados... Os professores náo podem ser autorizados a seguir seus caprichos na maneira como ensinam. Quando um método claramente superior a todos os outros métodos é descoberto, ele pode ser empregado sozinho. Negligenciar essa função e perdoar a negligência alegando o valor da liberdade do professor talvez tenha sido justificável sob o nosso empirismo anterior, quando os supervisores eram apenas professores promovidos e os cientistas sabiam pouco mais sobre padrôes e métodos que a maioria dos profissionais da área. (BOBBIT, 1913, p. 54-55).

Para Bobbitt (1913, p. 89), a "liberdade do professor deve ser estritamente limitada", devido à necessidade de métodos padronizados, eficientes. Bobbitt (1913, p. 87-93) chegou a sugerir que os alunos que estão estudando caligrafia devem ser testados "pelo cronômetro quanto à velocidade [...] para determinar qual dos modos de distribuiçấo dos sessenta minutos de tempo para o ensino 
da escrita é superior". Da mesma forma, Ellwood Cubberley, um influente administrador educacional, e superintendente das escolas públicas de São Francisco, escreveu em $1916 \mathrm{em}$ seu livro Public School Administration: "as nossas escolas são, em certo sentido, fábricas em que as matérias-primas (crianças) devem ser transformadas em produtos para atender às diversas demandas da vida" (KARIER, 1972, p. 158).

Para Joseph S. Taylor, superintendente distrital das escolas em Nova York, que escreveu em 1912:

(1) O estado como empregador deve cooperar com o professor como empregado, pois este nem sempre compreende a ciência da educação, (2) o estado fornece especialistas que supervisionam o professor e sugerem os processos que são mais eficazes e econômicos; (3) o sistema de tarefas funciona tão bem na escola quanto na fábrica, cada série sendo uma determinada quantidade de trabalho a ser realizado em um determinado período; (4) cada professor que realiza a tarefa recebe um bônus, não em dinheiro, mas na forma de uma avaliação que pode ter valor em dinheiro; (5) aqueles que são incapazes de fazer o trabalho são eliminados. (TAYLOR apud CALLAHAN, 1962, p. 103).

Sob este sistema, o principal meio pelo qual a eficiência dos professores deveria ser avaliada era a testagem de seus alunos. Assim, uma grande ênfase foi colocada no desenvolvimento de padrôes rígidos acompanhados por testes padronizados, começando pouco antes da Primeira Guerra Mundial. A NEA National Education Association (Associação Nacional de Educação) estabeleceu um Committee on tests and standards of efficiency in schools and school systems (Comitê de Testes e Padróes de Eficiência para Escolas e Sistemas Escolares) em 1911. Isso coincidiu com o movimento pela realizaçáo de testes de QI e várias formas racistas, levemente disfarçadas, de avaliaçãoo ${ }^{12}$ (CALLAHAN, 1965, p. 100-101).

Essa primeira tentativa de criar um sistema de ensino padronizado e dominado pelas corporaçôes foi fomentando pelas novas fundaçôes filantrópicas, fundaçóes isentas de impostos que surgiram neste período. Industriais milionários como Andrew Carnegie, John D. Rockefeller e Henry Ford 
fundaram fundaçôes privadas, destinadas a empregar financiamento filantrópico para alavancar grandes mudanças sociais, contornando o papel do governo. A Fundação Carnegie exerceu grande influência nos movimentos de eugenia e testagem. Ela investiu 6.424.000 dólares americanos em testagem ao longo de 1954. Em 1965, ela iniciou o desenvolvimento do programa de testagem, a NAEP - National Assessment of Educational Progress (Avaliação Nacional do Progresso Educacional). A Fundação Rockefeller, por sua vez, contribuiu fortemente para a criação do Educational Testing Service (Educational Testing Service), nos anos 1930 e $1940^{13}$.

\section{O Fracasso Inicial do Movimento pela Educação Corporativa}

Mas, apesar da forte influência exercida, no início do século XX, pelas corporaçôes monopolistas e pelas fundações filantrópicas sobre o desenvolvimento de um modelo corporativo para as escolas, cheio de padróes e testagem rígidos, as escolas públicas mantiveram-se, em muitos aspectos, fora do seu controle. As escolas foram, muitas vezes, o foco de lutas democráticas engendradas por professores progressistas, pais e comunidades. A educação manteve seu financiamento público, permaneceu descentralizada e sujeita às pressōes da comunidade. Os professores eram profissionais mal pagos em um campo de trabalho intensivo, onde tinham uma autonomia considerável e frequentemente identificavam-se com as crianças da classe trabalhadora. Os sindicatos de professores desenvolveram-se, permitindo aos professores de escolas públicas estabelecer um mínimo poder de barganha sobre seus salários e condiçôes de trabalho.

O sistema de escolarização capitalista resultante apresentava defeitos muito graves. Como uma sociedade profundamente segregada, os Estados Unidos permaneceram institucionalmente racistas - constituindo "A Vergonha da Nação" "14, como colocou Jonathan Kozol (2005) em seu livro de 2005 sobre o contínuo papel da estratificaçấo racial nas escolas dos EUA. O currículo foi muitas vezes degradado para atender às necessidades das corporaçôes por uma força de trabalho não qualificada e dócil.

No entanto, nos interstícios, os professores progressistas lutaram contra os piores aspectos do sistema tentando, apesar de tudo, atender às necessidades reais das crianças. The American Teacher, que se tornou o periódico da American Federation of Teachers (Federaçăo Americana de 
Professores), publicou em 1912 um artigo crítico à administração científica nas escolas, que argumentou:

A organização e os métodos das escolas assumiram a forma de empreendimentos comerciais que evidenciam a nossa vida econômica. Submetemo-nos à arrogância dos "grandes homens de negócios" e aceitamos os seus critérios de eficiência segundo sua própria avaliação, sem questionamentos. Consentimos em medir os resultados de açóes educacionais em termos de preço e produto - as condiçóes que prevalecem na fábrica e na loja de departamentos. Mas a educação, por lidar [...] com individualidades, não é análoga a um processo de fabricação padronizável. A educaçáo deve medir a sua eficiência não em termos [...] de tantos alunos-hora por cada dólar de salário; ela deve medir a sua eficiência em termos de aumento de humanismo, aumento da capacidade para fazer, aumento da capacidade de apreciar. (CALLAHAN, 1962, p. 121).

Assim, a educação permaneceu como um campo altamente disputado, com educadores, pais e membros da comunidade freqüentemente organizandose em oposição ao avanço da escolarização capitalista. Mudanças nas condições sociais deram origem a uma série de movimentos educacionais progressistas: o movimento pela educação democrática e experimental, associado a John Dewey na década de 1920 e 1930; o movimento pela dessegregação escolar na Era dos Direitos Civis e o movimento pela escola livre na década de 1960 e 1970. Escrevendo o livro Democracy in Education, de 1916, Dewey (1916, p. 51) declarou: "A educação não é subordinada a nada além de mais educação. O melhor produto da escolarização é a inclinação a aprender a partir da própria vida e a fazer com que as condiçôes de vida possibilitem a todos que aprendam no processo de viver".

O ano de 1916 marcou o nascimento do radical TU - New York Teachers Union (Sindicato dos Professores de Nova York). Construindo alianças com os pais e as comunidades, o TU lutou para acabar com a discriminação racial e a pobreza, reconhecendo que estas eram as principais barreiras para o sucesso dos alunos. Assim, visava uma filosofia educacional que implicava na transformaçáo de toda a sociedade. Representando uma poderosa alternativa - 0 que hoje poderia ser chamado de sindicalismo como movimento social ${ }^{15}-0$ 
TU foi acusado de ser comunista e extinto na Guerra Fria. Em torno de 1.100 funcionários de escolas foram chamados para interrogatório e mais de 400 foram demitidos ou expulsos da profissão. Em 1950, o New York Board of Education (Conselho de Educação de Nova York) aprovou a notória Resolução Timone, que proibia o TU de operar nas escolas(TAYLOR, 2009-, 2011).

Embora nenhum desses movimentos progressistas de ensino tenham sido capazes de transformar o ensino fundamental e médio dos EUA de maneira verdadeiramente emancipatória - ou de impedir que o sistema educacional como um todo se degenerasse ainda mais, à medida que a desigualdade, a pobreza, o racismo institucional e a desaceleração econômica afundavam cada vez mais as escolas ao final do século XX - eles obtiveram êxito em manter a educação dentro da esfera pública, sustentando valores democráticos básicos e preservando a esperança e a possibilidade de um futuro educacional mais igualitário.

\section{Estagnação econômica e ataques às escolas públicas}

O que mudou o cenário decisivamente para pior foi o início da estagnação econômica, começando com a recessão de 1974-75 e continuando com uma tendência declinante de crescimento econômico desde então. $\mathrm{O}$ crescimento real da economia nos Estados Unidos caiu, década após década, a partir dos anos 1970, exercendo uma pressão crescente sobre a educação. $\mathrm{O}$ total das despesas públicas em educação $\mathrm{K}-12^{16}$, considerado em termos de porcentagem do PIB, cresceu na década de 1960 e início da década de 1970, atingindo 4,1 por cento em 1975 , apenas para cair a 3,6 por cento uma década depois, em 1985. O percentual da receita da escola pública proveniente do governo local caiu de 53 por cento em 1965 para 44 por cento em 1985 devido a uma revolta generalizada contra os impostos sobre propriedade. Consequentemente, o financiamento centralizou-se nos recursos dos estados (HUNGERFORD; WASSMER, 2004, p. 10).

As escolas, por sua vez, foram forçadas a lidar com déficits crescentes da sociedade. A porcentagem de crianças americanas vivendo na pobreza aumentou de 14,4 por cento em 1973 para 22,7 por cento em 1993; enquanto a proporção de crianças pobres vivendo em extrema pobreza - definida como a metade do índice oficial de pobreza - aumentou de cerca de 30 por cento em 1975 para mais de 40 por cento em 1993. Um número crescente de crianças cada vez mais pobres chegou às escolas públicas, trazendo com elas 
mais necessidades urgentes, o que levou a maiores pressōes sobre os limitados recursos da escola (CHILDREN'S, 2010, p. b-3; BERLINER, 2006, p. 958).

A resposta à deterioração das condiçóes das escolas no período neoliberal, caracterizada por cortes nos gastos sociais, foi uma ênfase ainda maior em padróes e avaliaçóes. Escolas começaram a funcionar sob princípios mais corporativos, voltados para o mercado e foram cada vez mais privatizadas por meio da introdução de várias iniciativas conservadoras em defesa da school choice (escolha escolar), incluindo vouchers escolares e escolas charter. Iniciativas em defesa dos vouchers escolares surgiram com a proposta de Milton Friedman - famosa em seu livro, de 1962, Capitalism and Freedom - para que o governo distribuisse vouchers aos pais que equivalessem aos custos da educação pública de seus filhos, tornando possível enviá-los à escola de sua escolha. O principal objetivo era permitir que os fundos do governo subsidiassem a educaçáo privada. Este foi um ataque direto à educação pública. Em contraste, as escolas charter, que são financiadas com recursos públicos embora sejam geridas privativamente, não mais dirigidas pelos distritos escolares, mas ainda tecnicamente consideradas como escolas públicas, constituíram o que veio a tornar-se uma aproximação mais sutil à privatização, surgindo nos anos $1980^{17}$.

Na década de 1980, uma poderosa coalizão política conservadora, liderada por interesses corporativos, foi organizada contra as escolas públicas. Ronald Reagan buscou instituir os vouchers escolares, enquanto frequentemente indicava seu desejo de fechar o U.S. Department of Education (Departamento de Educação dos Estados Unidos), criado como um departamento em nível de gabinete durante a administração Carter. Reagan nomeou uma National Commission on Education (Comissão Nacional de Educação), que emitiu seu relatório, A Nation at Risk, em 1983. Sua mensagem era que o sistema educacional dos EUA estava fracassando devido às suas próprias contradições internas (nenhuma menção foi feita à desaceleração do crescimento econômico, à desigualdade crescente, ao aumento da pobreza etc.). Nas palavras de $A$ Nation at Risk (GARDNER, 1983):

Se uma potência inimiga tentasse impor à América o desempenho educacional medíocre que se apresenta atualmente, poderíamos muito bem ter compreendido esta ação como um ato de guerra. Temos permitido que isso aconteça a nós mesmos [...]. Na realidade, nós temos cometido um ato irrefletido e unilateral de desarmamento educativo. 
A administração Reagan, que iniciou uma enorme escalada militar por causa da Guerra Fria enquanto diminuia os impostos sobre os ricos e as corporações, usou a retórica de reduzir o vertiginoso déficit federal para justificar o abandono do apoio federal às escolas - incluindo um corte de 50 por cento nos fundos federais do Título $\mathrm{I}^{18}$ para as escolas em distritos de baixa renda (BRAMHALL, 2011). O final dos anos 1980 e os anos 1990 viram as primeiras mudanças dramáticas em direção a sistemas mais rígidos de padronização, responsabilizaçáo (accountability) e avaliaçáo, apoiados por mecanismos coercitivos, em estados como Kentucky e Texas (este último sob a administração de George W. Bush). Essa abordagem geral à reforma educacional foi elaborada pelo governo federal durante as administraçóes de George H.W. Bush e Clinton, e materializou-se como um importante programa nacional bipartidário para a transformação do ensino fundamental e médio na presidência de George W. Bush ${ }^{19}$.

Três dias após sua posse, em 2001, Bush revelou seu programa NCLB. A legislaçáo NCLB, promulgada em 08 de janeiro de 2002, tinha centenas de páginas embora fosse simples em sua concepção, consistindo em sete componentes principais: (1) todos os estados deveriam desenvolver seus próprios testes e três níveis de desempenho (básico, proficiente, e avançado), sendo que a proficiência deveria ser determinada separadamente por cada estado; (2) a fim de receber recursos federais para educaçáo, os estados eram obrigados a aplicar testes para avaliar os estudantes de terceira à oitava séries anualmente quanto à proficiência em leitura e em matemática, e a desagregar as pontuaçóes em termos de condição de baixa renda, raça, etnia, nível de dificuldade de aprendizagem e proficiência limitada em língua inglesa; (3) cada estado deveria elaborar um cronograma mostrando como 100 por cento de seus alunos atingiriam a proficiência até 2014; (4) todas as escolas e distritos escolares foram obrigados a demonstrar o AYP - adequate yearly progress (progresso anual adequado) para cada subgrupo desagregado em direçáo à meta de 100 por cento de proficiência em 2014; (5) uma escola que náo alcançasse o AYP para todos os subgrupos estaria sujeita à onerosas penalidades que aumentariam em cada ano subseqüente. No quarto ano, a escola estaria sujeita a "ação corretiva", exigindo mudanças curriculares, mudanças no quadro de funcionários, ou um ano escolar mais longo. No quinto ano, uma escola que ainda não atingisse o AYP seria obrigada a "reestruturar-se"; (6) uma escola que fosse obrigada a reestruturar-se tinha cinco opçôes, todas elas equivalentes: (a) transformar-se em uma escola 
charter, (b) demitir o diretor e os funcionários e substituí-los por outros; (c) entregar o controle da escola à gestão privada; (d) ceder o controle da escola para o estado, ou (e) "qualquer outra grande reestruturação da administração da escola" (a maioria das escolas e distritos escolares que foram forçados a se reestruturar escolheram a última alternativa, relativamente indefinida, na esperança de evitar as outras opçóes); (7) todos os estados foram obrigados a participar no teste federal, a NAEP - National Assessment of Educational Progress (Avaliação Nacional do Progresso Educacional) que, apesar de não ter consequências para as escolas e distritos escolares, foi concebido para constituir uma forma de verificação externa sobre os sistemas de testagem estaduais.

O número de escolas forçadas a se reestruturar sob a NCLB aumentou ano a ano. Em 2007 e 2008, 3.500 escolas em todo o país estavam em fase de planejamento ou implementaçáo de reestruturaçáo, um salto de 50 por cento em relaçáo ao ano anterior. Em 2010, o número de escolas nos Estados Unidos que não conseguiram alcançar o $\mathrm{AYP}$ sob as regras da NCLB aumentaram para 38 por cento, em comparaçáo com os 33 por cento no ano anterior ${ }^{20}$.

Apesar da NCLB colocar novas responsabilidades e expectativas sobre as escolas e professores, a despesa total do governo dos EUA com a educação fundamental e média considerada em termos de percentagem do PIB não aumentou. Ela havia aumentado na década de 1990, atingindo um pico de 4,2 por cento em 2001, assim que a NCLB foi divulgada, apenas para cair novamente nos primeiros anos da NCLB para 4,0 por cento em 2006, abaixo do nível de 1975 (HUNGERFORD; WASSMER, 2004; UNITED STATES, 2010, p. 288). A legislação NCLB trouxe exigências muito pesadas sem oferecer nenhuma forma de financiamento, obrigando as escolas públicas administradas pelos distritos a assumir enormes custos adicionais, sem os meios para fazêlo. William Mathis, diretor executivo do National Education Policy Center (Centro Nacional de Políticas em Educação), em Boulder, Colorado, e um ex-superintendente das escolas de Vermont, estimou que seria necessário um aumento de 20-35 por cento no orçamento atual da educação K-12 em todo o país para financiar a NCLB. Em vez disso, o financiamento da educação aumentou apenas marginalmente - permanecendo igual ou mesmo diminuindo, tanto considerando-o como uma parcela do PIB ou como uma parcela dos gastos públicos (excluindo despesas militares) (MATHIS, 2003; KARP, 2004).

Em relação aos grandes distritos escolares urbanos, a tentativa mais célebre de reforma escolar ao estilo NCLB foi a reestruturação escolar feita pelo 
prefeito Michael Bloomberg em Nova York. Bloomberg, um bilionário detentor de um patrimônio de US\$ 18 bilhôes, classificado como o décimo terceiro indivíduo mais rico nos Estados Unidos em 2011, acumulou seus bilhóes por meio da construção de um império da mídia voltado para notícias financeiras, Bloomberg LP21. Em seu material de campanha, Bloomberg declarou que as escolas estavam em um "estado de emergência". Após a sua eleição para prefeito, ele imediatamente procurou transformar a educação K-12 segundo critérios corporativo-financeiros. As pontuações dos testes de leitura e matemática foram o foco central; todas as outras áreas do currículo foram depreciadas. As escolas públicas que foram reprovadas deveriam tornar-se escolas charter. No entanto, apesar da reestruturação e privatização das escolas realizadas por Bloomberg, os testes federais NAEP mostraram que os estudantes de Nova York não alcançaram avanços significativos, seja em leitura ou em matemática, no período entre 2003 e 2007 (RAVITCH, 2000).

\section{Filantropia de risco e educação de valor agregado}

Bloomberg não estava sozinho entre os bilionários interessados na reforma escolar neste período. No século XXI, era do capital monopolista-financeiro e informacional, surgiu, entre os maiores círculos corporativos, a convicção de que a educação poderia agora ser totalmente gerenciada conforme critérios técnico-científicos e financeiros, tornando possível: (1) obter controle sobre o processo de trabalho dos professores; (2) subordinar a escolarizaçáo à criação de uma força de trabalho mais diferenciada e rotinizada; e (3) privatizar a educaçâo pública (ou ao menos apoderar-se de tanto quanto for possível de maneira a não encontrar grande resistência). Na era digital, a burocratização, o tracking $g^{22}$ e a testagem passaram a ser consideradas práticas viáveis como nunca haviam sido antes. No centro deste processo estava a centralização do processo de trabalho de ensino, de maneira que todo o processo de concepção da prática pedagógica seria removido dos educadores e controlado por autoridades superiores, conforme a administração científica clássica. As escolas públicas foram incentivadas a investir cada vez mais recursos em "tecnologia" em detrimento do corpo docente, no âmbito de um projeto taylorista atualizado em que os professores deveriam tornar-se meros apêndices de máquinas inteligentes.

O sonho utópico da educação cientificamente administrada, que não se materializou completamente no século XX, finalmente parecia possível sob o 
capitalismo digital do século XXI. "Devido aos avanços tecnológicos", Diane Ravitch, ex-Secretária Adjunta de Educação do governo George H.W. Bush, observou que "muitos estados e municípios têm a capacidade de atribuir os resultados dos testes de alunos específicos a professores específicos e [...] muitos irão utilizar essa informação para responsabilizar os professores pela ascensão ou declínio das notas de seus alunos" (RAVITCH, 2000, p. 151-152). A linguagem dominante no novo movimento conservador pela reforma escolar passou a ser aquela do "ensino com valor agregado" e se os professores "'agregaram valor' aos seus alunos" - o novo critério para avaliar o desempenho dos professores e determinar o montante da remuneração por desempenho. Agregar valor, neste caso, significava nada mais que aumentar as pontuaçôes dos testes, como um substituto para o crescimento de capital (KOHN, 2010).

A liderança do movimento corporativo pela reforma escolar do século XXI - chegando ao ponto de ocupar-se do papel do governo a este respeito veio de quatro grandes fundaçóes filantrópicas, encabeçadas pelos principais representantes do capital monopolista-financeiro, informacional e varejista: (1) a fundação Bill \& Melinda Gates; (2) a Fundação da Família Walton; (3) a fundação Eli \& Edythe Broad; e (4) a fundação Michael \& Susan Dell. Elas são amplamente caracterizadas como um novo tipo de fundação, conhecida como "filantropia de risco" (um nome derivado de capitalismo de risco) - também chamado de "filantrocapitalismo" (RAVITCH, 2000, p. 199; OUR, 2011-). As organizaçôes de filantropia de risco são geralmente distintas das fundaçôes mais tradicionais pela sua abordagem mais agressiva, voltada para investimentos. $\mathrm{O}$ dinheiro é canalizado diretamente para projetos escolhidos, evitando o repasse de recursos tradicional. Adota-se uma abordagem de valor agregado, exigindo retorno rápido com base em critérios empresariais. Organizaçóes filantrópicas de risco são notavelmente agressivas em sua influência direta sobre as políticas governamentais, apesar de serem isentas de impostos.

A Fundação Gates, criada por Bill Gates, da Microsoft, tinha cerca de US\$ 33 bilhôes em ativos no ano de 2010, além de outros US\$ 30 bilhôes do capitalista financeiro Warren Buffet, distribuídos em contribuiçóes anuais. Em 2008, a Fundação Walton, representando os donos das Lojas Wal-Mart, tinha US\$ 2 bilhões em ativos. A Fundação Broad - dirigida por Eli Broad, um bilionário do mercado imobiliário e financeiro que vendeu sua empresa SunAmerica em 1999 para a AIG (que posteriormente faliu e foi socorrida com recursos públicos) por US\$ 18 bilhōes - tinha US $\$ 1,4$ bilhão em ativos no 
ano de 2008. E a Fundação Michael \& Susan Dell, criada por Michael Dell, fundador e CEO da Dell - tinha um pouco mais de US \$ 1 bilhão em ativos em $2006^{23}$.

A direção tomada pela Fundação Dell permanece intimamente ligada em suas atividades à Dell, que é uma das maiores empresas de tecnologia que atuam como fornecedoras das escolas públicas. A Fundação Dell trabalha em estreita colaboração com as outras três fundaçóes filantrocapitalistas (as fundaçōes Gates e Broad estão entre suas maiores doadoras). Ela dá ênfase especial à "gestão de desempenho": uma abordagem orientada ao uso de tecnologia da informação como a base da responsabilização das escolas. Isso está diretamente ligado aos próprios objetivos econômicos da Dell no mercado educacional, uma vez que a Dell é a segunda, depois da Apple, no ranking de fornecimento de hardware e infra-estrutura tecnológica para escolas K-12. A Fundação Dell afirma que está auxiliando as escolas urbanas a usar "a tecnologia para reunir, analisar e transmitir informações" afim de melhorar a gestão escolar ${ }^{24}$. É uma forte defensora da escolha escolar, da presença de EMOs - Education Management Organizations (Organizações de Gestão da Educação), com fins lucrativos nas escolas charter e do desenvolvimento imobiliário de escolas charter ${ }^{25}$.

A Fundação Broad é especializada no treinamento de um enorme e novo quadro de reformadores educacionais neoliberais-capitalistas, vindos principalmente de fora da área da educação (por meio do recrutamento de profissionais da área empresarial, legal, militar etc.). Seu objetivo é colocálos em cargos superiores de gestâo e de superintendência escolar. O Broad Center for the Management of School Systems (Centro Broad para a Gestâo de Sistemas Escolares) consiste em dois programas: a Broad Superintendents Academy (Academia Broad de Superintendentes), especificamente voltada ao treinamento de superintedentes de escolas e a encontrar vagas para os mesmos nas grandes cidades; e a Broad Residency in Urban Education (Residência Broad em Educação Urbana), criada para inserir os seus diplomados em altos cargos administrativos nos distritos escolares. A Fundação Broad acelera sua alocação oferecendo complementar os salários de seus diplomados, tornando-os mais atraentes aos conselhos escolares mais sobrecarregados e permitindo-lhes contratar profissionais de nível corporativo. A contrataçáo de diplomados da Broad também é percebida como uma forma pela qual os distritos escolares podem tornar-se elegíveis para financiamentos adicionais da Fundaçáo Broad. O Broad Institute for School Boards (Instituto Broad para Conselhos Escolares) 
tem como missão específica a reciclagem dos membros eleitos dos conselhos escolares por todo o país, de modo a levá-los a adotar o novo modelo corporativo de gestão escolar (HAIMSON, 2011; BARKAN, 2011).

Em 2009, os diplomados da Academia Broad, de acordo com seu site, preencheram 43 por cento de todas as vagas de direçáo dos grandes centros urbanos. A Fundação Broad é uma forte defensora da privatização da educação, e está particularmente interessada em acabar com os sindicatos de professores, instituindo a remuneração por desempenho e, de maneira geral, desprofissionalizando a educaçáo, que acredita poder ser administrada em puros termos empresariais, proletarizando a força de trabalho. Em 2009, Eli Broad declarou em um discurso em Nova York, "Nós não sabemos nada sobre ensino ou sobre currículo de leitura ou sobre qualquer outra coisa relacionada. Os assuntos que dominamos são gestão e governança"26.

A Fundação Broad promove o que Naomi Klein (2007) chama de "doutrina do choque", ou uma forma de "capitalismo de desastre", destruindo o sistema de educação pública a fim de abrir caminho para sua privatização. Em abril de 2009, Seattle Education publicou um guia para os pais, How to tell if your School is infected by the Broad Virus (Como saber se a sua escola está infectada pelo Vírus Broad), em seu site. Entre os sintomas do vírus "Broad" foram listados:

As escolas em nosso distrito são subitamente fechadas [...]. A repetição das frases "desigualdade do desempenho escolar" (achievement gap) e "diminuir a desigualdade do desempenho escolar" (closing the achievement gap) em documentos distritais e declaraçôes públicas [...]. O aumento repentino no número de consultores externos pagos. $\mathrm{O}$ aumento do número de escolas públicas transformadas em escolas charter de gestão privada [...]. A adoção de material didático de qualidade inferior em matemática [...]. Possivelmente também em artes da linguagem. A liderança distrital declara que o problema mais significativo no distrito, subitamente, são os professores! [...] Quantidades excessivas de testes introduzidos e impostos aos seus filhos [...] Seu conselho escolar começa a apresentar sinais da Síndrome de Estocolmo. Eles votam em sintonia com o superintendente [...]. Bolsas surgem das fundaçóes 
Broad e Gates em apoio ao superintendente e seu "Plano Estratégico". A Fundação Gates concede ao seu distrito bolsas para coisas técnicas [...]. e/ou para a "eficácia" do professor ou para estudos sobre as escolas charter. (HOW, 2011).

A Fundação Walton reflete a perspectiva da corporação Wal-Mart, que ergueu-se à custa de trabalho mal remunerado, virulenta oposição aos sindicatos e a criaçáo de um poder monopolista no setor de varejo. A Fundaçáo Walton busca quebrar, de todas as formas possíveis, o monopólio da escola pública sobre a educação por meio de ataques aos sindicatos de professores, fomento de escolas charter de gestão privada, escolha escolar etc. Ravitch observa: "Ao examinar as contribuiçôes da Fundação Família Walton, é óbvio que os membros da família procuram criar, apoiar e promover alternativas para a educação pública. Sua agenda consiste em escolha escolar, concorrência, e privatizaçăo" (RAVITCH, 2010, p. 202-203).

Nos últimos anos, a Fundação Gates, decididamente a maior destas fundações filantrocapitalistas, adotou uma agenda muito próxima à da Fundação Broad, e as duas frequentemente operam em conjunto. Bill Gates declarou que não há nenhuma conexão entre a qualidade dos professores e fatores como sua certificação, experiência, cursos de pós-graduação ou mesmo amplo conhecimento do assunto a ser ensinado (RAVITCH, 2010, p. 219). A Fundação Gates tem investido centenas de milhóes de dólares no apoio a grupos lobistas da educação destinados a pressionar a política pública, todos visando reestruturar a educação pública, fomentar escolas charter, incentivar a privatização e acabar com os sindicatos de professores. Assim, ela concedeu milhōes de dólares para a Teachers Plus, uma organização que apóia a reestruturação da educação, enquanto argumentava que as demissōes de professores deveriam ser baseadas em avaliações (resultados dos testes), ao invés de tempo de serviço, como insistem os sindicatos (GRASS, 2001; INDIANAPOLIS, 2011). A Fundação Gates também apóia o Teach for America (Ensine pela América), um programa que recruta candidatos diretamente das universidades, coloca-os em um treinamento intensivo de cinco semanas, e envia-os para ensinar em escolas de baixa renda, geralmente por dois ou três anos - sem o benefício de um curso de formaçáo de professores, ou de uma aprendizagem significativa que possibilite conseguir uma certificação profissional (TEACHER, 2011). 
A Fundação Gates concedeu US\$ 90 milhóes para financiar o programa Renaissance 2010, uma "estratégia de turnaround"27, então dirigida pelo CEO das escolas públicas de Chicago, Arne Duncan. A iniciativa de Duncan de implantar a doutrina do choque em Chicago estava em conssonância com o relatório financiado pela Fundação Gates, The Turnaround Challenge $(\mathrm{O}$ Desafio de Turnaround). Duncan, agora Secretário da Educação dos EUA, tem chamado The Turnaround Challenge de a "bíblia" da reestruturação escolar, e integrou-o com a política federal oficial, tornando-o a base do programa para as escolas de Obama, Race to the Top (Corrida para o Topo). Em seu relatório anual de 2009/2010, a Fundação Broad declarou: "[...] a eleição do presidente Barack Obama e a nomeação de Arne Duncan, ex-CEO da Escolas Públicas de Chicago, como o Secretário de Educação dos EUA, marcou o auge de esperança para nosso trabalho na reforma educacional. De várias maneiras, nós sentimos que as estrelas finalmente se alinharam". Até fevereiro de 2009, tanto Duncan quanto o ex-assessor-chefe de economia de Obama, Lawrence Summers, estavam no quadro de diretores da divisão de educação da Fundação Broad.

Duncan, imediatamente após tomar posse, tratou de nomear um diretor de envolvimento filantrópico no Gabinete do Secretário da Educação, declarando o Departamento de Educação, literalmente, "aberto para negócios." Ele preencheu os escalóes superiores do departamento com associados das fundaçóes Gates e Broad (BARKAN, 2011, p. 53-55). Joanne Weiss, que dirigiu a Race to the Top Competition (Competiçấo Corrida para o Topo) na Administraçáa de Obama e agora é chefe de gabinete de Duncan, foi diretora do NewSchools Venture Fund - uma organização de reestruturação escolar fortemente financiada pelas fundaçóes Gates e Broad (OHANIAN, 2010).

$\mathrm{Na}$ Race to the Top, a administração Obama ofereceu um grande financiamento adicional para um número limitado de estados (no final, 11 estados do Distrito de Columbia foram declarados vencedores), escolhendo apenas aqueles que conformaram-se aos seus objetivos de reestruturação no que diz respeito à testagem, escolas charter, privatização e remoção do direito de estabilidade no emprego do professor. Durante o processo de seleção, a Fundação Gates analisou os planos de reforma iniciais em cada estado e escolheu seus quinze favoritos, oferecendo a cada um até US\$250 milhóes para contratar consultores que iriam escrever propostas para o Race to the Top. Como resultado, os educadores se queixaram de que Gates estava 
escolhendo os vencedores e os perdedores para o programa federal. A Fundação Gates, portanto, mudou suas táticas e disse que iria oferecer o dinheiro para quaisquer estados que cumprissem todos os seus oito critérios, um dos quais era restringir o direito de estabilidade no emprego do professor.

A filosofia central subjacente ao Turnaround Challenge da Fundação Gates (CALKINS, 2007), que representa a política semi-oficial da administração Obama, é que "a demografia não precisa determinar o destino" ou que "a qualidade da escola pode superar o código postal". Este argumento, por vezes apresentado como a filosofia "No Excuses" (Sem Desculpas) é proferido repetidamente no movimento educacional corporativo (THERNSTROM, 2003) ${ }^{28}$. Contradizendo os contundentes resultados de quatro décadas de pesquisa em educação - iniciando em 1966, com o Relatório Coleman, que determinou que quando os fatores socioeconômicos são controlados, "as diferenças entre as escolas são responsáveis por apenas uma pequena fração das diferenças no desempenho do aluno" - os reformistas conservadores agora procuram colocar a responsabilidade por "diminuir a desigualdade do desempenho escolar" exclusivamente sobre as próprias escolas.

$\mathrm{Na}$ verdade, o estatístico conservador William Sanders (apud HOLLAND, 2001), da Universidade da Carolina do Norte, o principal defensor da "avaliação de valor agregado" nas escolas, declarou categoricamente: "De todos os fatores que estudamos - tamanho da sala de aula, etnia, localização, pobreza - todos eles tornam-se triviais em face da eficácia dos professores". Tais concepçôes podem fazer sentido caso o problema fosse simplesmente aumentar o desempenho médio dos alunos, o que certamente depende dos professores. Em vez disso, o problema é diminuir a disparidade entre os diferenciais no desempenho médio dos estudantes de origens raciais e de classe muito desiguais (incluindo os alunos pobres e sem-teto), o que significa exigir praticamente o impossível das escolas e dos professores ${ }^{29}$.

Na verdade, adotar uma filosofia conservadora "no excuses" em relação à desigualdade do desempenho escolar é fechar os olhos para a realidade fundamental - a pobreza infantil. É isso, diz David Berliner (2006), professor de educação da Universidade Estadual do Arizona, que constitui o "grande problema da educação americana hoje" ${ }^{30}$. Como o economista Richard Rothstein (2004, p. 1-2) escreveu em seu Class and Schools: 
A conclusão de que a desigualdade do desempenho escolar é produto de "escolas ineficazes" (failing schools) [...] é enganosa e perigosa. Ela ignora como as características de classe social em uma sociedade estratificada como a nossa podem, de fato, influenciar a aprendizagem nas escolas [...]. Por quase meio século, a associação entre desvantagem social e econômica com a desigualdade do desempenho escolar dos alunos era bem conhecida pelos economistas, sociólogos e educadores. A maioria, entretanto, evitou a implicaçáo óbvia desta compreensão - elevar o desempenho das crianças de classes mais baixas exige a melhoria das condiçóes sociais e econômicas de suas vidas e não apenas a reforma escolar.

No entanto, o novo zeitgest da educação conservadora insiste que estes fatores socioeconômicos mais amplos que afetam as vidas das crianças em idade escolar podem facilmente ser anulados ou ignorados. Embora às vezes reconheça que a desigualdade, a discriminaçáo racial e a pobreza afetam negativamente o desempenho escolar, esses fatores, dizem-nos, de forma alguma determinam esse desempenho. Segundo a teoria, é assim possível criar escolas que, sistematicamente, apagam essas desvantagens de estudantes carentes. Os reais bloqueios para o desempenho do estudante que devem nos preocupar, então, são aqueles pelos quais as próprias escolas são responsáveis: a falta de responsabilização e avaliação e o ensino de baixa qualidade ${ }^{31}$. Desigualdade de classe, pobreza infantil, deterioraçáo urbana, racismo, etc. devem ser tomados em conta apenas em termos de uma filosofia da "cultura da pobreza", reciclada dos anos 1960, em que os estudantes pobres e pertencentes a minorias são ensinados a adotar os valores/cultura "superiores" da classe média branca como a solução para o sucesso ${ }^{32}$. Refletindo uma crença capitalista central, a Fundação Gates insiste que as escolas podem "elevar" todos os alunos sem levar em conta quaisquer desvantagens que eles possam trazer consigo ${ }^{33}$.

The Turnaround Challenge começou por identificar a avalanche de escolas que necessitavam de reestruturação sob a NCLB, número que ele projetou já estar atingindo cinco mil, ou cerca de 5 por cento de todas as escolas do país entre 2009 e 2010 . O principal problema, obviamente, era que 35 por cento de todos os estudantes do país e dois terços dos estudantes minoritários freqüentam escolas muito pobres, as quais tradicionalmente apresentam desempenho 
inferior. Pobreza, o relatório afirma, constitui um obstáculo significativo para as escolas diminuirem a desigualdade do desempenho escolar, mas ela não é necessariamente uma barreira intransponível. Em casos muito raros, estatisticamente insignificantes, conforme indicado em uma série de diagramas de dispersão, poucas escolas puderam ser encontradas que apresentassem ao mesmo tempo altos índices de pobreza e alto desempenho (high poverty and high performance - HPHP). Do ponto de vista de The Turnaround Challenge, essas escolas HPHP foram importantes porque elas refutaram que a pobreza fosse uma barreira absoluta ao progresso escolar.

A Fundação Gates presume que estas raras escolas HPHP são escolas charter ou escolas que seguem modelo análogo, livres de conselhos escolares, currículos escolares tradicionais, professores certificados e sindicatos de professores, operando segundo princípios de eficiência voltados para a alta produtividade/valor agregado. A resposta, portanto, parece óbvia: "'charterizar' ('charterize') as escolas ineficazes"(CALKINS, 2007, p. 16). Mas como esta não era a opção prontamente escolhida pelas escolas e distritos escolares, foi necessário levá-las a escolher "o caminho da charterização"- ou a "adoção de regras e dirigentes que sigam o modelo charter" (CALKINS, 2007, p. 23) nas escolas dirigidas por distritos escolares. Isto, entâo, poderia "tornar-se o tâo aguardado meio pelo qual as escolas públicas adaptar-se-iam ao que parece funcionar em escolas charter de alto desempenho" (CALKINS, 2007, p. 2728) - e, portanto, serem progressivamente charterizadas.

A administração Obama tem seguido esta filosofia da Fundação Gates rigorosamente, promovendo escolas charter de gestão privada em oposição às escolas públicas administradas por distritos e tentando levar as escolas distritais a, pelo menos, adotar características semelhantes às escolas charter. Por conseguinte, ela ameaçou restringir o financiamento federal da educação para estados que limitavam o número de escolas charter (RAVITCH, 2010).

Escolas charter são nominalmente escolas públicas, na medida em que dependem de financiamento público e são obrigadas a admitir qualquer estudante. Elas operam sob um "charter" ou contrato, que é um documento legal, estabelecendo um sistema de responsabilização entre o órgão público que as autoriza e seus administradores. Portanto, elas são, em essência, escolas contratadas que operam de forma independente do conselho escolar eleito e do distrito escolar, livres da maioria dos regulamentos que regem as escolas públicas administradas por distritos. Embora, virtualmente, qualquer um possa abrir 
uma escola charter (pais, professores, membros da comunidade, organizaçōes sem fins lucrativos ou corporações com fins lucrativos), na prática, na prática elas estão sendo geridas como se fossem empresas e estão sendo dominadas por interesses de investidores. Isto resulta ou do apoio financeiro e orientaçấo de grandes fundaçóes privadas, como no caso de muitas organizaçóes charter sem fins lucrativos, ou de escolas sendo administradas diretamente por EMOs com fins lucrativos.

Após a devastação do furacão Katrina em 2005, Nova Orleans rapidamente charterizou suas escolas públicas. Como Danny Weil explicou em 2010, em Disaster Capitalism: Revisiting the Charter Schooling and Privatization of Education in New Orleans,

Em menos de 19 meses [após o Katrina] a maioria das escolas públicas tradicionais de Nova Orleans tinha sido 'charterizada' e todos os professores de escolas públicas não somente foram despedidos à velocidade de um relâmpago, como também seus benefícios trabalhistas foram destruídos juntamente com todos os contratos existentes. (WEIL, 2010).

Mais da metade dos alunos estavam matriculados em escolas charterizadas em 2008, comparado aos 2 por cento no momento em que o Katrina atingiu a região, e muitas dessas escolas são dirigidas por EMOs com fins lucrativos (CHARTER, 2008).

Barbara Miner (2010), editora-chefe da Rethinking Schools, escreve que embora o movimento pela escola charter tivesse raízes progressivas, ele acabou recorrendo àqueles "comprometidos com uma agenda em prol do mercado livre e da privatização. Na última década, estes privatizadores passaram a dominar o movimento pela escola charter". Ou, como declarou a distinta educadora Deborah Meier (2011), autora de In Schools We Trust:

A promessa que as escolas charter nos ofereceram em seu início foi rapidamente abandonada à medida que elas transformaram-se em grandes sucursais indiferenciadas, não sendo administradas por 'mamães e papais' da maneira como imaginávamos, mas pelos bilionários mais poderosos do planeta. 
As escolas charter do Harlem que foram enaltecidas no documentário de 2010 contra as escolas públicas e os sindicatos de professores, intitulado Waiting for Superman, são administradas por um par de organizações guardachuva de gestão escolar charter (MINER, 2010). Uma delas, a Success Charter Network, tem um conselho de nove membros, dos quais sete são administradores de fundos de hedge e de empresas de investimento, um é sócio-gerente da NewSchools Venture Fund (fortemente financiada pelas Fundaçôes Gates e Broad), e outro é um representante do Institute for Student Achievement (uma organização especializada em reestruturação escolar sem fins lucrativos que recebe fundos substanciais da AT \& T). Náo há pais, professores ou membros da comunidade neste conselho. Como o New York Times observou, os fundos de hedge formam o "epicentro" do movimento charter em Nova Iorque (HASS, 2009). O capital financeiro, obviamente, interessa-se pelas escolas charter, que são: (1) financiadas com recursos públicos, porém geridas de forma privada e alavancadas em áreas estratégicas por grandes fundaçōes; (2) não sindicalizadas em sua maioria (e também contra sindicatos); (3) voltadas para testagem, coleta de dados e tecnologia; (4) geralmente abertas para um modelo corporativo de organização; e (5) receptoras de grandes fundos, o que exige gestáo financeira.

As escolas charter, ainda que sem fins lucrativos, podem participar de estratégias lucrativas. Como Miner (2010) escreve: "Há aqueles que irão ganhar dinheiro com a Harlem's Children Zone" (a segunda das duas principais organizaçóes charter em Harlem enaltecidas no filme Waiting for Superman):

A organização sem fins lucrativos dispunha de 194 milhóes de dólares em ativos líquidos de acordo com declaração de imposto de 2008. Quase US\$ 15 milhóes em poupança e investimentos temporários, e outros 128 milhôes de dólares investidos em um fundo de hedge. Dado que a maioria dos fundos de hedge operam no que é conhecido como uma estrutura de taxa 2-20 (uma taxa de administração de 2 por cento e 20 por cento dos eventuais lucros), alguns fundos de hedge sortudos renderão milhóes de dólares em cima da Harlem's Children Zone, seja qual for o ano. (MINER, 2010).

Apesar de toda a atenção voltada às escolas charter, consideradas como instrumentos para diminuir a desigualdade do desempenho escolar, 
os avanços educacionais previstos não se materializaram. Em 2003, o teste federal NAEP indicou que os estudantes de escolas charter não apresentaram nenhum progresso mensurável sobre os estudantes de escolas públicas, entre alunos de origens raciais/étnicas semelhantes; enquanto que, no caso de alunos pobres da quarta série, as escolas públicas superaram as escolas charter em leitura e matemática. Assim, de acordo com seus próprios padrôes rígidos de escolarização, medida por testes padronizados, o movimento da escola charter está longe de ser bem sucedido.

O estado da Filadélfia anunciou em 2009 que suas escolas charter foram um fracasso. Embora seis das vinte e oito escolas de ensino fundamental e médio de gestão privada haviam superado as escolas públicas administradas pelos distritos, dez apresentaram um desempenho inferior em relação às escolas distritais. Pelo menos quatro das escolas charter estavam sob investigação criminal federal por má administraçáo financeira, conflitos de interesse e nepotismo. Os administradores de algumas escolas charter da Pensilvânia criaram empresas privadas para vender produtos para suas escolas charter (RAVITCH, 2010).

Mesmo quando as escolas charter apresentam altas pontuaçóes nas avaliaçóes, elas ainda podem ser acusadas de não matricular a quota estipulada de alunos com algum tipo de necessidade especial. Um estudo realizado em 2002/2003 por Jack Buckley e Mark Schneider (2007), respectivamente os comissários atual e anterior do National Center for Education Statistics (Centro Nacional de Estatísticas Educacionais) do Departamento de Educação dos EUA, mostrou que, das trinta e sete escolas charter em Washington, estudantes de educação especial foram sub-representados em vinte e quatro, enquanto principiantes da língua inglesa (cuja língua materna não é o inglês e que ainda não têm capacidade para realizar as tarefas comuns de sala de aula em inglês) foram sub-representados em vinte e oito.

O programa de escolas charter mais célebre é o Knowledge is Power Program - KIPP (Programa Conhecimento é Poder), que tem se beneficiado de um fluxo constante de fundos provenientes das fundaçóes Gates, Walton e Broad. Assim como as escolas charter mais bem-sucedidas, a KIPP matricula os alunos por sorteio, o que tende a trazer apenas os melhores e mais motivados alunos de famílias igualmente motivadas. As escolas KIPP são criteriosas e exigem que os estudantes passem 60 por cento a mais de tempo na escola do que em uma escola pública tradicional, a fim de cumprir requisitos específicos. 
Estas exigências pesadas de tempo de trabalho expulsam os estudantes mais carentes e de menor desempenho, que acabam voltando para as escolas públicas normais. Uma pesquisa sobre as escolas KIPP de São Francisco em 2008 mostrou que 60 por cento dos estudantes que começaram a estudar em uma escola KIPP na quinta série não permaneceram até o final de oitava série. Como Ravitch afirma:

[...] as escolas públicas normais devem aceitar todos os que se canditatam, incluindo os estudantes que deixam as escolas KIPP. Elas não podem expulsar as crianças que não estudam muito, ou as crianças que têm muitas faltas, ou as crianças que são desrespeitosas, ou as crianças cujos pais são ausentes ou negligentes. Elas têm de encontrar maneiras de educar até mesmo aquelas crianças que não querem estar lá. Esse é o dilema da educação pública. (RAVITCH, 2010, p. 135-136).

Em Nova Orleans, o fracasso das escolas charter em atender alunos com dificuldades de aprendizagem resultou em um processo legal administrativo interposto pelo Southern Poverty Law Center, em nome de 4.500 alunos com dificuldade de aprendizagem. A denúncia imputa às escolas charter de Nova Orleans a violação sistemática do Individuals with Disabilities Education Act (MOCK, 2004; CHILDREN..., 2010) ${ }^{34}$.

As escolas charter são caracterizadas não apenas por alto índice de evasão por parte de seus alunos, como nas escolas KIPP, mas também por alto índice de evasão por parte de seus professores, que frequentemente protestam contra o excesso de trabalho e os baixos salários. Um estudo nacional sobre escolas charter de 1997 a 2006 descobriu que o índice de evasão entre os novos professores de escolas charter é de quase 40 por cento anualmente, enquanto que entre o conjunto de professores de escolas charter a taxa é de 25 por cento por ano, cerca do dobro do índice de evasão dos professores de escolas públicas (MIRON, APPLEGATE, 2007). Em geral, professores de escolas charter recebem salários inferiores aos dos professores de escolas públicas, mesmo desconsiderando os melhores benefícios que estes recebem. Uma pesquisa sobre as escolas públicas de Michigan em 2001 revelou que o salário médio anual para professores de escolas charter era de US\$31.185, em comparação com os US\$ 47.315 pagos aos professores de escolas públicas normais (BRACEY, 2003). 
Um número significativo de escolas charter é administrado por EMOs. Essas organizaçóes com fins lucrativos administram escolas charter com o objetivo de acumular capital. Essas empresas têm utilizado uma série de estratégias para aumentar os lucros, começando pela redução dos custos trabalhistas. As escolas charter normalmente não são sindicalizadas, pagando salários mais baixos. Os professores que lá trabalham, como aqueles oferecidos pela Teach for America, muitas vezes não têm formação profissional. As EMOs não são obrigadas a participar em sistemas de aposentadoria estatal e, enquanto elas contratam a salários relativamente competitivos, os benefícios sáo poucos e dificilmente ocorrem aumentos salariais por tempo de serviço. O tamanho da classe é frequentemente maior. Também é comum que as EMOs contratem empresas que remuneram mal seus funcionários e que dependam mais intensamente dos pais voluntários. As EMOs tendem a reduzir os serviços extras oferecidos às crianças: programas de merenda escolar, transporte e atividades extracurriculares. Elas oferecem um currículo mais restrito, voltado para a testagem de habilidades básicas. Todas estas medidas são consideradas formas padronizadas de proteger $\mathrm{o}$ lucro líquido (PLANK, 2000; BRACEY, 2003). Uma série de estudos recentes de alto nível tem indicado que escolas charter administradas por EMOs são propensas a níveis mais elevados de segregação racial (MIRON, 2010).

\section{O Complexo Educacional-Industrial}

A reestruturação das escolas públicas tem dado um grande impulso ao setor de educação privada, que atualmente é visto como uma área em crescimento, prometendo enormes lucros. Em 16 de maio de 2011, CNNMoney.com informou que a "estrela do rock do mercado de trabalho", após o setor da saúde, desde o início da Grande Recessão no final de 2007, tem sido o setor da educação, que criou 303.000 empregos nos últimos quatro anos, principalmente em serviços na área da educação e faculdades estaduais (ISIDORE, 2011) ${ }^{35}$.

Já em 2000, a Bloomberg Business Week publicou um relatório sobre investimentos em educação que projetou uma tendência geral de mercantilização e privatização das escolas. Scott Soffen, analista de educação da Legg Mason, uma empresa global de gestão de ativos, foi citado dizendo que "o grande concorrente [do setor de educação privada] é o governo e, ao longo do tempo, o setor com fins lucrativos irá sistematicamente apropriar-se deste ramo de atividade do governo" (SYMONDS, 2000). 
O setor de educação tem sido, naturalmente, um forte apoiador dos novos sistemas de avaliação e testagem ${ }^{36}$. Em 2005, ThinkEquity Partners LLC publicou um relatório intitulado New Industry, New Schools, New Market: K-12 Education Industry Outlook, 2005, para a Education Industry Association. Ela constatou que, em 2005, o setor da educação representou "uma oportunidade nacional/interna de negócios no mercado de educação K-12 [US\$ 500 bilhôes]" de "US\$ 75 bilhôes, ou 15 por cento de todas as despesas da educação K-12". Como resultado das novas medidas dos governos federal e estadual relativas aos padróes, à testagem e à responsabilização, além do crescimento das escolas charter, era esperado que o setor de educaçáo K-12 crescesse para 163 bilhôes de dólares (20 por cento do mercado de educaçáo K-12) dentro de dez anos. Já em 2005, aquisiçôes do setor de educação para as escolas K-12 incluíram 6,6 bilhões de dólares em infra-estrutura e hardware, US $\$ 8$ bilhôes em materiais didáticos, e US $\$ 2$ bilhôes em avaliação (sistemas de testagem). Os gastos com tecnologia - constando entre as categorias citadas acima desde que os softwares foram incorporados ao conteúdo didático - foi estimado em US\$ 8,8 bilhôes. O relatório sobre o setor da educação concluiu que tudo isso refletiu uma "aceitação e integração mais profunda entre educação e negócios". Muitas "novas formas de fazer dinheiro" foram se abrindo.

As empresas que provavelmente mais se beneficiaram da expansão do setor de educação voltado para a educação K-12 foram as grandes corporaçóes, em especial a Apple, Dell, IBM, HP, Compaq, Palm, e Texas Instruments (tecnologia); Pearson, Harcourt, McGraw-Hill, Thomson, e Houghton Mifflin (conteúdo didático); CTB McGraw, Harcourt Assessment, Thomson, Plato, Renaissance (avaliação) e Scholastic, Plato, Renaissance, Scientific Learning, e Leapfrog (conteúdo didático complementar). Certo número de pequenas empresas de tecnologia e de empresas promissoras que trabalham com conteúdo didático complementar foram classificadas no relatório sobre educaçáo K-12 da ThinkEquity como prontas para serem adquiridas por empresas maiores. Na verdade, as grandes empresas de conteúdo didático estão engolindo as pequenas empresas. Apenas nove empresas responderam por 87 por cento do mercado de testagem (BRACEY, 2005). Os setores de equipamentos de computação e de avaliação foram considerados como de rápido crescimento (THINKEQUITY, 2005).

O renomado pesquisador educacional e crítico Gerald W. Bracey emitiu um relatório em 2005, intitulado No Child Left Behind: Where Does the Money Go? , enfocando o papel do grande capital, corrupção e propinas. Um fato 
simbólico da influência exercida pelo setor da educação privada foi a reunião de George W. Bush, em seu primeiro dia na Casa Branca (poucos dias antes da revelação da NCLB), com o seu amigo de família íntimo e membro da equipe de transição de Bush, Harold McGraw III, CEO da McGraw-Hill. A Business Roundtable, representando duzentas das maiores corporações dos Estados Unidos, foi uma forte defensora da NCLB. O CEO da State Farm Insurance, Edward Rust, Jr., que orquestrou a maior parte do apoio da Business Roundtable à NCLB, era simultaneamente Presidente da Força-Tarefa da Educaçáo, da Business Roundtable, um membro da diretoria da McGraw-Hill, e um membro da equipe de transição de Bush. De acordo com Bracey, toda a esfera da expansão do setor educacional com fins lucrativos, sob a NCLB, exibiu um "padrão duplo impressionante"(BRACEY, 2005, p. 18-19) em que "o tratamento super exigente dado às escolas públicas" (BRACEY, 2005, p. 34), era "contrastado com o tratamento negligente dado às corporaçóes que fornecem materiais ou que prestam serviços que, por exigência legal, são utilizados pelas escolas" (BRACEY, 2005, p. 41).

\section{Educação para Além do Capital ${ }^{37}$}

Atualmente, a verdadeira natureza da luta pela escolarização nos Estados Unidos evidencia-se na difamaçáo diária de professores e sindicatos de professores exercida pelo movimento neoliberal de reforma escolar e pela mídia corporativa ${ }^{38}$. Falando com professores em Chicago, Ravitch (que trabalhou nas administraçôes de George H. W. Bush e Clinton, e foi originalmente um grande defensor da NCLB) declarou:

A reforma escolar corporativa é um disfarce para o verdadeiro objetivo: livrar-se dos sindicatos. A reforma escolar corporativa clama às legislaturas para que revertam os direitos de negociação coletiva, que eliminem os sindicatos. Porém, uma vez eliminados, não haverá mais ninguém para falar pelas crianças, pelas condiçôes de trabalho [...]. (SCHMIDT, 2011).

Quem aplaude quando as escolas são fechadas? Fundos de hedge de Wall Street, os Democratas pela Reforma Educacional (Democrats for Education Reform - lobos em pele de cordeiro), Stand for Children [que recebe milhóes 
de dólares da Fundação Gates], a Billionaire Boys Club (Gates, Walton, Broad), vários grupos de intelectuais e pesquisadores (think tanks) de Washington, quase todos financiados pela Fundação Gates e que influenciam muitos dos principais conselhos editoriais. É um movimento de reforma corporativa circular. E eu afirmo que, sempre que falamos desta reforma educacional, estaremos nomeando-a mais corretamente como uma reforma corporativa (SCHMIDT, 2011).

As novas reformas escolares capitalistas visam principalmente os professores e seus sindicatos por uma razão: professores, por via de regra (embora muitas vezes politicamente passivos), opõe-se fortemente a nova escolarização corporativa que está sendo imposta aos seus alunos e à taylorização de seu próprio processo de trabalho. Os professores geralmente vêem-se como profissionais da educaçáo, mas hoje estão sendo rapidamente proletarizados. Assim, eles são, potencialmente, a oposição mais poderosa ao plano de reestruturaçáo escolar e à mercantilização de crianças em idade escolar. Por esta razão, os novos sistemas de testagem destinam-se prioritariamente aos professores. Eles servem como avaliaçóes náo tanto dos próprios alunos, mas do grau ao qual os professores têm sucumbido à taylorização - e, portanto, constituem a principal arma na tentativa de tomar o controle da prática da educaçáo dos professores. Duncan (2010) já declarou várias vezes que uma das principais conquistas da Race to the Top foi forçar os estados a abandonar as restriçóes sobre o uso de testes de avaliação de alunos para avaliar os professores. Como Ravitch (2010, p. 177) observou em The Death and Life of the great American School System:

Sindicatos [de professores] têm muitos críticos, incluindo alguns integrantes que se queixam pelo fato de seus líderes não conseguirem proteger os professores contra os reformadores corporativos [...]. Mas os críticos mais citados na mídia vêem os sindicatos como o principal obstáculo para a reforma educacional. Eles culpam os sindicatos por resistirem ao uso de pontuaçóes em testes como forma de avaliar os professores. Eles querem que os administradores tenham a liberdade de demitir professores cujo os escores dos testes dos alunos não melhorem e de substituí-los por novos professores que poderiam levantar esses escores. Eles querem usar os escores dos testes como o instrumento decisivo de avaliação. 
Aqui é útil retornarmos ao ponto fundamental - levantado na década de 1970 na obra de Bowles e Gintis (1976), Schooling in Capitalist America, de que há uma correspondência aproximada, em qualquer período histórico, entre as relaçôes sociais de produção e as relaçôes sociais da educação. Consideradas a partir deste ponto de vista político-econômico geral, as condiçôes que levaram ao ataque neoliberal às escolas podem ser atribuídas ao período histórico atual de estagnação econômica, financeirização e reestruturação econômica, características da era do capital monopolista-financeiro. A desaceleração do crescimento econômico, que começou nos anos 1970, enfraqueceu a capacidade do trabalho de lutar por meios puramente econômicos, ao mesmo tempo enfraquecendo o poder político dos trabalhadores, enquanto as forças corporativas conservadoras reforçavam sua hegemonia sobre a sociedade. $\mathrm{O}$ crescimento relativo do capital financeiro e informacional, estimulado pela estagnação da produção, criou um novo impulso para o taylorismo digital e para a gestão financeira rigorosa nas escolas. Ao mesmo tempo, a desigualdade, a pobreza e o desemprego aumentavam, enquanto o capital transferia os prejuízos econômicos para a classe trabalhadora e os pobres. Quando os novos problemas decorrentes do crescimento lento, da desigualdade crescente e do aumento da pobreza infantil associaram-se às restriçōes mais rigorosas sobre os gastos do Estado, as escolas entraram em rápido declínio. As escolas públicas, consituindo a melhor rede de proteção social disponível para a maioria das crianças e das comunidades, foram forçadas a agir para compensar o colapso do tecido social e econômico.

Com a "revolt of the haves" ${ }^{39}$ que se desenrolou neste período, o tradicional financiamento local das escolas com base nos impostos sobre propriedade ruiu. Os estados e o governo federal foram forçados a assumir o financiamento das escolas, o controle local foi reduzido e um modelo corporativo-financeiro passou a dominar juntamente com as tradicionais metas de gestáo corporativa. O fracasso da testagem ${ }^{40}$ e da responsabilizaçáo como formas de promover melhorias, mesmo em termos de seus próprios critérios estritos, levou a ataques ainda mais intensificados aos professores e aos sindicatos de professores como se eles fossem a fonte do problema. O estouro da bolha financeira que começou em 2007 e a Grande Recessão que se seguiu debilitaram as escolas e os sindicatos de professores, criando um estado de emergência generalizado.

Embora a porcentagem da educação K-12 em relação ao PIB tenha aumentado ligeiramente para um aparente pico de 4,3 por cento em 2009, isso 
não reflete um maior compromisso geral com a educação, mas sim a relativa debilidade da economia privada em relação aos gastos do governo no contexto da Grande Recessão. Mais indicativo da tendência de deterioração nos gastos com educação nesse período é o fato de que os gastos com o ensino fundamental e médio dos EUA cairam de 22,7 por cento dos gastos totais do governo em 2001 para 21,7 por cento em 2005 e para 21,0 por cento em 2009 - com todos os indicativos de que a porcentagem em relação aos gastos totais do governo continua a cair ${ }^{41}$.

Nessa situação de rápida deterioração, o ataque aos professores e a destruição de seu moral podem ser entendidas como fatais para o sistema público de educação, já que na sociedade capitalista os professores em geral têm procurado promover a educação (e não a mera escolarização) por um compromisso com as crianças, frequentemente chocando-se contra um sistema alienado. Os professores adotaram práticas contra-hegemônicas e sustentaram, por puro comprometimento, um sistema escolar em colapso que, sem os seus esforços frequentemente extraordinários, certamente teria desmoronado. A maioria dos professores entrevistados pela National Education Association (Associação Nacional de Educação) em seu mais recente Status of the American Public School Teacher (NEA, 2010), trabalham, pelo menos, dez horas não compensadas (além da jornada padrão de 40 horas de trabalho por semana) a cada semana e complementam o orçamento e os recursos da sala de aula com seu próprio dinheiro, totalizando em média 443 dólares ao ano (DESPITE, 2003). Sem o forte compromisso social dos professores, o sobrecarregado sistema de ensino público certamente teria sucumbido às suas próprias contradições há muito tempo.

A maioria dos professores, ao longo das últimas décadas, acostumaram-se a estar na linha da frente, lidando com os efeitos da crise econômica e a guerra de classe e racial contra os alunos. A criação de um programa de avaliação nacional, voltado principalmente aos professores e sindicatos de professores, com o objetivo de privatizar o sistema educacional e transformar a massa de alunos em trabalhadores servis para a indústria trouxe a educação pública para o centro da crise estrutural do sistema. Muitos professores foram demitidos, enquanto outros fugiram das escolas públicas agonizantes.

Considerando os efeitos do agravamento das condiçôes socioeconômicas sobre a educação pública, qualquer referência a diminuição da desigualdade do desempenho escolar que não remeta fundamentalmente aos problemas sociais 
mais amplos e aos seus efeitos nas escolas não passa de uma brincadeira cruel. Resumindo as conclusóes de décadas de pesquisa em educação no Teachers College Record em 1995, Jean Anyon (1995, p. 69) comentou:

Tornou-se cada vez mais evidente que várias décadas de reforma educacional não conseguiram trazer melhorias substanciais para as escolas localizadas em regiōes mais pobres das cidades dos EUA. As análises mais recentes sobre reforma escolar mal-sucedida (e prescriçôes para a mudança) isolaram aspectos educacionais, regulatórios, ou financeiros da reforma do contexto social de pobreza e racial em que estas escolas estão inseridas [...] a base estrutural para o fracasso dessas escolas é política, econômica e cultural, e deve ser alterada antes que projetos de melhoria escolar significativos possam ser implementados com sucesso. Reformas educacionais não podem compensar a devastação da sociedade.

Nas últimas décadas, a resposta dos professores sobrecarregados de trabalho do país à "devastação da sociedade" e aos ataques sofridos pelas escolas geralmente tem sido usar a pouca energia que lhes resta para auxiliar seus alunos enquanto evitam a atividade política organizada. Mas isso pode estar mudando. A resistência política atual nas escolas exercida por professores, pais, alunos e membros da comunidade parece estar emergindo finalmente nos Estados Unidos - embora seja muito cedo para saber o que isso possa indicar.

Já em 2010, Karen Lewis, professor de química do ensino médio e líder do Caucus of Rank-and-File Educators - CORE, ganhou uma eleição conturbada para se tornar presidente do Sindicato dos Professores de Chicago, depondo o anterior, da velha guarda, que já havia sido eleito por duas vezes consecutivas. Isto ocorreu devido a um desejo por parte dos professores de Chicago, cidade natal de Arne Duncan, de lutar por seus empregos, por condiçóes de trabalho e pelo futuro da educaçáo para seus alunos. A CORE surgiu como uma rebeliáo popular contra o legado da "turnaround" de Chicago levada a cabo por Duncan, caracterizada pelo fechamento e charterização das escolas. Este fato, portanto, representa um afastamento em relaçáo a uma estrutura sindical mais ligada aos interesses das empresas, em direção a um sindicato mais politizado (LEWIS, POTTER, 2010). 
Em abril de 2011, em Detroit, os estudantes protestaram para impedir o fechamento da premiada Catherine Ferguson Academy (Academia Catherina Ferguson), uma escola pública para adolescentes grávidas e mães que ostenta uma taxa de 100 por cento de aceitaçáo nas faculdades em um distrito onde um terço de todos os alunos nem mesmo terminam o ensino médio. Os protestos conseguiram atenção nacional depois que alguns dos alunos e seus apoiadores, envolvidos em uma manifestação pacífica ${ }^{42}$, foram presos. Detroit como um todo está enfrentando o fechamento em massa de escolas sob as ordens do gerente de emergência das Escolas Públicas de Detroit, Robert Bobb, um egresso da Academia Broad de Superintendentes, formado em 2005, que recebe um suplemento salarial anual de US\$145.000,00, pago pelas fundações Broad e Kellogg. Não é de estranhar que alguns têm chamado a estratégia de gestão de Bobb de "lei marcial financeira": em abril de 2011, todos os 5.466 professores públicos de Detroit escolares foram demitidos (AHMED, 2011; ROBERT 2010).

A intensa luta de classes em Wisconsin em 2011, provocada pela tentativa do governador Scott Walker de eliminar sindicatos do setor público nesse estado, pode marcar uma nova fase no conflito entre trabalhadores e capital. Em maio de 2011, como parte da revolta geral contra as açóes de Walker, o ativista educacional radical, Peterson Bob, um professor da quinta série e um editor fundador da Rethinking Schools, foi eleito presidente da Milwaukee Teachers' Education Association (Associação Educacional de Professores de Milwaukee), composta de 8.000 membros (RICHARDS, 2011).

Ao longo de maio de 2011, alunos, pais e professores participaram de protestos nacionais contra a dilasceração do ensino público. Em 9 de maio de 2011, milhares de professores, estudantes e apoiadores iniciaram um "Estado de Emergência" de uma semana pela educação pública na Califórnia. Em um protesto de professores em 9 de maio no capitólio estadual em Sacramento, Califórnia, sessenta e cinco alunos, professores e apoiadores foram presos, evento seguido pela prisão de mais vinte e sete em 12 de maio, incluindo o presidente da California Teachers Association (Associação de Professores da Califórnia) (MERCER, 2011; AHMED, 2011). Os protestos sinalizaram uma aliança entre aluno e professor (como trabalhador) nesta área que é particularmente alarmante para os poderes constituídos.

$\mathrm{Na}$ sua previsão de orçamento de maio, o governador da Califórnia Jerry Brown respondeu a estes protestos crescentes contra o ataque às escolas 
indicando que ele pretende colocar freios na testagem estadual descontrolada, o que pode ser um importante ponto de partida. Brown declarou: "Os professores são forçados a inibir sua própria criatividade e envolvimento com os alunos enquanto concentram-se em ensiná-los para o teste. Administradores estaduais e federais continuam a centralizar a qualificação do ensino longe da sala de aula". Brown diz que pretende "[...]reduzir a quantidade de tempo dedicado à testagem estadual nas escolas" e "[...] restaurar o poder dos gestores escolares, professores e pais" (CODY, 2011). Brown almeja suspender o financiamento para o sistema estadual de coleta de dados longitudinais para a educação (projetado para integrar as bases de dados existentes, a fim de facilitar a retenção dos dados de avaliação de longo prazo dos alunos), e dar fim ao planejamento de bases de dados dos professores. Ele já havia declarado, como Procurador Geral da Califórnia, que os problemas reais que afetam as "[...] escolas de baixo desempenho em situação precária" estão "[...] profundamente enraizados nas condiçōes sociais e econômicas da comunidade" (CODY, 2011).

O objetivo estratégico de um movimento de resistência à privatização da escola pública náo deve ser simplesmente defender o sistema escolar existente - mas fazer uso desse estado de emergência para criar a base de uma abordagem verdadeiramente revolucionária ao processo educativo, baseada em escolas comunitárias. Isso poderia ocorrer sob o lema promovido pelo James and Grace Lee Boggs Center, em Detroit: Another Education is Possible (Outra Educação é Possível). Como Grace Lee Boggs escreveu, precisamos envolver nossos filhos no processo de construção da comunidade, incluindo a educação, "com a mesma audácia com que o movimento dos direitos civis os envolveu em atividades de dessegregação". O teórico da educação radical Bill Ayers apela pela reconstrução do modelo de "educaçáo libertadora" e das freedom schools ${ }^{43}$ (escolas libertárias), em oposiçáo a No Child Left Behind e a Race to the Top, rearticulando "o ideal de que cada ser humano tem valor infinito". Isso significa enfatizar, como educadores radicais têm feito historicamente, um processo de aprendizagem com envolvimento do aluno - reconhecendo, em conformidade com Marx (1974) e Paulo Freire (1970), que a resposta à pergunta: "Quem educa o educador?" vem, fundamentalmente, da pedagogia da libertação, em que os próprios alunos são os principais protagonistas ${ }^{44}$.

Nós devemos entender isso como parte de uma luta global. As mesmas reformas corporativas de escolarizaçáo estáo sendo exportadas para todo o mundo capitalista, o Brasil, sendo apenas mais um exemplo (FORERO, 2011). 
As apostas são extremamente elevadas. Em seu artigo, Why Socialism, publicado no primeiro número da Monthly Review, em maio de 1949, Albert Einstein escreveu:

Eu considero a incapacitaçáo dos indivíduos como o pior mal do capitalismo. Todo o nosso sistema educacional decorre deste mal. Uma atitude exageradamente competitiva é inculcada no estudante, que é ensinado a venerar o sucesso a qualquer custa como uma preparação para uma futura carreira. Estou convencido de que há apenas uma forma de eliminar estes sérios males, especificamente por meio da constituição de uma economia socialista, acompanhada de um sistema educacional que seria orientado para objetivos sociais. Em tal economia, os meios de produção são organizados pela própria sociedade e são utilizados de forma planejada. Uma economia planejada, que adeque a produção às necessidades da comunidade, distribuiria o trabalho a ser feito entre todos aqueles que podem trabalhar e garantiria o sustento a cada homem, mulher e criança. A educação do indivíduo, além de promover suas próprias capacidades inatas, tentaria desenvolver nele um sentido de responsabilidade pelo seu semelhante em vez da glorificaçáo do poder e do sucesso como ocorre em nossa sociedade presente. (EINSTEIN, 1949, p. 14).

Para Einstein (1949), a educação e o socialismo estavam intimamente, dialeticamente ligados. Tal visão da educação - relacionada com a transformaçáo e o planejamento social - significava que a educação necessitava, em sua opiniấo, fazer parte de toda a nossa vida e não ficar confinada à esfera da escolarização.

Acredito que devemos nos preparar hoje para uma longa revolução, para criar, entre outras coisas, uma nova educação ligada à comunidade, e desenvolvida a partir das necessidades reais das pessoas.

A melhor forma de alcançar tal educação "centrada na comunidade e baseada na pessoa" (BOGGS, 2011, p. 140), situada primeiramente nas escolas públicas, mas estendendo-se para a sociedade como um todo, será por meio da criaçáo do respeito mais amplo possível pela educação, constituindo, ao mesmo 
tempo, um modo de vida, uma chave para a emancipação humana e uma base indispensável para a criação de um mundo de igualdade real ${ }^{45}$.

\section{Notas}

${ }^{1}$ Ver John Bellamy Foster e Fred Magdoff (2009), The Great Financial Crisis. Uma visão mais completa da crise estrutural do capital deveria concentrar-se no fato de que o capital está pressionando os limites absolutos de todas as áreas, que se manifesta no crescimento da desigualdade (ao invés de igualdade real); no crescente conflito entre o Estado e a reproduçâo e preservação do sistema; e no engendramento de uma crise ecológica planetária. Ver István Mészáros (1995), Beyond Capital.

${ }^{2}$ Global Education Market. Diponível em: <http://apolloglobal.us $>$. Acesso em: 15 maio 2011.

${ }^{3}$ N. do T.: O sistema de ensino obrigatório nos EUA tem duração de 13 anos englobando a elementary school ou elementary education, que corresponderia ao ensino fundamental no Brasil e no qual o aluno ingressa com cinco anos (no kindergarten) e fica até a $8^{a}$ série, e a high school ou secondary education, que corresponde ao ensino médio no Brasil, e engloba da $9^{\mathrm{a}}$ à $12^{\mathrm{a}}$ série. Para facilitar a leitura, as referências à elementary school e elementary education serão traduzidas como "ensino fundamental" e "educação fundamental", bem como referências à secondary school e secondary education serão traduzidas como "ensino médio" e "educação média”.

${ }^{4}$ Uma abordagem etnográfica completamente diferente ao modo como "as crianças da classe trabalhadora conseguiram empregos da classe trabalhadora", foi fornecida em Paul E. Willis (1976), em Learning to Labour. Sobre a natureza geral do debate que surgiu no âmbito da sociologia da educação em relação ao trabalho de Bowles e Gintis, ver David L. Swartz (2003), From Correspondence to Contradiction and Change: Schooling in Capitalist America Revisited.

${ }^{5}$ Sherry Gorelick (1977), Undermining Hierarchy: Problems of Schooling in Capitalist America. Ver também Samuel Bowles and Herbert Gintis (1978), Reply to Sherry Gorelick. Em Bowles e Gintis (1978), deve ser observado que eles já abandonaram grande parte de sua análise original, 
adotando posiçóes mais conservadoras, alinhadas com uma mudança geral em seu ponto de vista. Na verdade, eles se distanciaram gradualmente de seu marxismo original, de maneira que em 2001 seus pontos de vista originais eram dificilmente perceptíveis tanto em tom como em conteúdo. Compare Samuel Bowles and Herbert Gintis (2002), agora apóiam tanto os vouchers escolares como as escolas charter, que fazem parte da agenda da reforma educacional conservadora. Ver Swartz (2003), From Correspondence to Contradiction and Change; Samuel Bowles and Herbert Gintis (1996), Efficient Redistribution.

${ }^{6}$ Bowles e Gintis (1976, p. 13, 48, 130-132; 1988).

${ }^{7}$ Bowles and Gintis (1976, p. 48-49, 131).

${ }^{8}$ Bowles and Gintis (1976, p. 131-40). Essa divisão tripartite dos mercados de trabalho foi apoiada por considerável número de trabalhos empíricos, que evoluiram para a análise do mercado de trabalho segmentado, desenvolvida por economistas radicais na década de 1970 e 1980.

${ }^{9}$ N. do T.: Grupo de oito instituições de ensino superior tradicionais do nordeste dos Estados Unidos que estão entre as de maior prestígio do país. A denominação é referência à hera (ivy) que recobre o exterior dos edifícios dessas escolas.

${ }^{10}$ Richard Edwards (1979, p. 44); Richard Du Boff (1989, p. 57-59).

${ }^{11}$ Veja a análise do Taylorismo em Harry Braverman (1998).

${ }^{12}$ Sobre os abusos associados à testagem de QI, ver Stephen Jay Gould (1996, p. 85-90).

${ }^{13}$ Karier (1972, p. 157-172), Testing for Order and Control; Bowles e Gintis (1976, p. 198).

${ }^{14}$ N. do T.: The Shame of the Nation - Título do livro em inglês.

${ }^{15} \mathrm{~N}$. do T.: Termo original em inglês - social movement unionism. O sindicalismo como movimento social não se limita à organização tradicional de trabalhadores na forma de sindicato, desenvolvendo-se justamente para responder aos novos arranjos trabalhistas em que as relaçóes empregatícias não existem ou não são claras.

${ }^{16}$ N. do T.: K-12 é uma abreviação de kindergarten (jardim de infância) e 
12a série, utilizada nos Estados Unidos, Canadá, Filipinas e Austrália para designar o conjunto do ensino fundamental e médio.

${ }^{17}$ Milton Friedman (1962, p. 91). As escolas charter foram fomentadas, inicialmente, tanto pelos liberais (incluindo o presidente da American Federation of Teachers, Al Shanker) quanto por seus equivalentes mais de direita. No entanto, foi o modelo conservador, mais voltado para o mercado e direcionado à privatizaçáo das escolas que veio a definir cada vez mais o movimento pela escola charter.

${ }^{18} \mathrm{~N}$. do T.: Original em inglês - Title I federal fundings. O Title I é um programa educacional fundado pelo U.S.Department of Education (Departamento de Educação dos Estados Unidos) que conta com financiamento federal, a fim de distribuir recursos para escolas e distritos educacionais com alta porcentagem de alunos provindos de famílias de baixa renda.

${ }^{19}$ Sobre Kentucky ver Edward B. Fiske (1991, p. 62-69).

${ }^{20}$ Diane Ravitch (2010, p. 15-21, p. 93-98, p. 104-105); Center for Educational Policy (CEP, 2011). Diane Ravitch (2000) foi, originalmente, uma crítica da esquerda em Left Back por supostamente alegar que as escolas não têm importância, e tem sido acusada por alguns da esquerda de ajudar a iniciar os atuais ataques conservadores às escolas. Ver Alan R. Sadovnik (2011).

${ }^{21}$ Michael Bloomberg. Forbes. Disponível em: <http://www.forbes.com/ profile/michael-bloomberg/>.

${ }^{22}$ N. do T: Prática difundida no sistema educacional dos Estados Unidos, que consiste na separação dos alunos em diferentes grupos (tracks) de acordo com seu desempenho escolar. Os grupos de alunos com melhor desempenho (high tracks) têm acesso a cursos mais exigentes, professores mais qualificados e melhores oportunidades de aprendizagem enquanto aos grupos de alunos com desempenho mais baixo (low tracks) são oferecidos currículos mais básicos e menos exigentes.

${ }^{23}$ Joanne Barkan, 2011, p. 50; Janelle Scott, 2009, p. 120-121; Ravitch, 2000, p. 212-217.

${ }^{24}$ Michael e Susan Dell Foundation, Urban Education. Disponível em: 
$<$ http://msdf.org>. Acesso em:17 maio 2011.

${ }^{25}$ Scott, 2009, p. 120; ThinkEquity Partners LLC (2005, p. 31).

${ }^{26}$ Ravitch, 2010, p. 213-217; Barkan, 2011, p. 50.

${ }^{27} \mathrm{~N}$. do T.: A palavra turnaround, neste contexto, traz a noção de reviravolta, mudança de direção no sentido oposto. No entanto, este termo é frequentemente utilizado em sua forma original na área da administraçáo em expressóes como "estratégia de turnaround" ou "turnaround empresarial", sendo também por vezes traduzido como reestruturação. Turnaround caracteriza uma situação empresarial que engloba três fases: a fase de declínio da empresa, a fase emergencial (ou fase de reduçáa) e a fase de reestruturação propriamente dita (ou fase de recuperaçáa).

${ }^{28}$ Ver crítica à ideologia “No Excuses” em Debra H. Meier, 2002, p. 145-146.

${ }^{29}$ James Samuel Coleman et al., 1966, p. 21-22. Ver crítica de Sanders em Richard Rothstein, 2004, p. 13-17.

${ }^{30}$ Elizabeth Cohen, professora de sociologia na Universidade de Stanford, introduziu a fraseologia da pobreza como "o grande problema inquestionado da educação em uma fala proferida em uma conferência organizada pela U.S. Office of Education Research and Improvement em 1996. Ver Bruce J. Biddle, 2001, p. 3.

${ }^{31}$ Para um resumo e uma crítica destas perspectivas alinhadas com a ideologia "no excuses", ver Rothstein, 2004, p. 61-83.

32 Ver Meier, 2002, p. 146.

33 "Uplift Education" é uma Charter Management Organization (Organização de Gestão de Escolas Charter) financiada pela Fundaçáo Dell.

${ }^{34}$ N. do T.: Lei federal dos Estados Unidos que rege a forma como os estados e os órgãos públicos devem proporcionar intervenção precoce, educação especial e demais serviços relacionados às crianças com dificuldades de aprendizagem e necessidades especiais.

35 Essas expectativas, no entanto, podem ser frustradas pelo fato de que os gastos com educação pública, particularmente a educaçáo K-12, estáo atualmente enfraquecendo rapidamente como resultado da Grande Recessão, da estagnaçáo econômica e dos cortes no financiamento estadual 
e local (HU; GEBELOFF, 2011).

${ }^{36} \mathrm{~N}$. do T.: Original em inglês - "high-stakes assessment and testing". A expressão high-stakes testing refere-se a testes com importantes consequências para o examinado como, por exemplo, a obtençáo de um diploma, uma bolsa de estudos ou uma licença para praticar determinada profissão.

${ }^{37}$ Esta frase foi extraída de István Mészáros, 2008, p. 248.

${ }^{38}$ Esse ataque aos professores pode ser conferido no prólogo do livro que acompanha o filme Waiting for Superman. No prólogo de nove páginas, três delas, um terço do texto, é dedicado a difamar professores e sindicatos de professores. Ver Karl Weber, 2010, p. 5-8.

${ }^{39}$ N. do T.: A expressão pode ser traduzida grosseiramente como "revolta dos que têm". O termo criado pelo jornalista socialista americano Robert Kuttner para designar a People's Initiative to Limit Property Taxation (Iniciativa Popular pela Limitaçấo dos Impostos sobre Propriedade). Também conhecida como Proposição 13, foi uma Emenda Constitucional do estado da Califórnia, promulgada em 1978 por meio de iniciativa popular que reduziu drasticamente a arrecadação local de impostos sobre propriedade.

${ }^{40} \mathrm{~N}$. do T.: Termo original em inglês - high stakes testing, já mencionado no item 18.

${ }^{41} \mathrm{~K}-12$ Education in the U.S. Economy (HUNGERFORD; WASSMER, 2004, p. 10): Tabela 2.1, Bureau of Economic Analysis, National Income and Product Accounts; Tabela 3.15.5 (Government Consumption Expenditures and Gross Investment by Function); e tabela 1.1.5 (Gross Domestic Product).

${ }^{42}$ N. do T.: Termo original em inglês - sit-in. Forma de protesto em que os participantes sentam-se em algum local estratégico e recusam-se a levantar ou sair do lugar até que sejam retirados a força, presos ou que suas reivindicaçóes sejam atendidas.

${ }^{43}$ N. do T.: Durante os meses de férias de verão de 1964 nos Estados Unidos, um grupo de mais de cem voluntários, brancos e negros, dirigiram-se ao Mississippi para iniciar uma campanha pelo direito de voto negro e pela 
fundação do Mississippi Freedom Democratic Party - MFDP (Partido Democrático pela Liberdade do Mississippi). Como parte dessa campanha, conhecida como Verão da Liberdade, foram desenvolvidas as freedom schools, em que professores voluntários ensinavam temas evitados pelas escolas públicas como história afro-americana e direitos constitucionais.

${ }^{44}$ Grace Lee Boggs, Bill Ayers. In Julia Putnam et al. Another Education is Possible. Detroit: James and Grace Lee Boggs Center. p. 39, 66, 70.

${ }^{45}$ Ver Mészáros, 2008, p. 237, 248.

\section{REFERÊNCIAS}

AHMED, Beenish. Fighting School Closures in Detroit. The American Prospect, 3 may 2011. Disponível em: < http://prospect.org/article/fightingschool-closures-detroit>.

ANYON, Jean. Race, Social Class, and Educational Reform in an inner City School. Teachers College Record, New York, v. 97, n. 1, fall 1995.

BARAN, Paul A.; SWEEZY, Paul M. Monopoly Capital. New York: Monthly Review Press, 1966. p. 309-310.

BARKAN, Joanne. Got dough? How billionaires rule our schools. Dissent Magazine, winter 2011.

BERLINER. David C. Our impoverished view of educational research. Teachers College Record, New York, v. 108, n. 6, jun. 2006.

BIDDLE, Bruce J. Poverty, ethnicity, and achievement in American schools. In: BIDDLE, Bruce J. Poverty (Ed.). Social class, poverty, and education. New York: RoutledgeFarmer, 2001.

BOBBITT, Franklin. The Supervision of City Schools. Chicago: University of Chicago Press, 1913.

BOGGS, Grace Lee. The next American revolution: sustainable activism for the twenty-first century. Berkeley: University of California Press, 2011.

BOWLES, Samuel; GINTIS, Herbert. Schooling in Capitalist America. New York: Basic Books, 1976. 
BOWLES, Samuel; GINTIS, Herbert. Reply to Sherry Gorelick. Monthly Review, New York, v. 30, n. 6, p. 59-64, nov. 1978.

Prologue: The Correspondence Principle. In: COLE, Mike (Ed). Bowles and Gintis Revisted. New York: The Falmer Press, 1988. p. 1-4. dec. 1996.

Efficient Redistribution. Politics and Society, v. 24, n. 4, p. 307-342,

Schooling in Capitalist America Revisited. Sociology of Education, n. 75, n. 1, p. 1-18, jan. 2002.

BRACEY, George W. The war against America's public schools. Boston: Pearson Education, 2003.

No child left behind: where does the money go? Tempe, $A Z$ :

Education Policy Research Unit, jun. 2005. Disponível em: <http://epsl.asu. edu/epru/documents/EPSL-0506-114-EPRU.pdf>.

BRAMHALL, Stuart Jeanne. The history of school privatization movement. Open Salon, 15 mar. 2011. Disponível em: <http://open.salon.com/blog/ stuartbramhall/2011/03/15/the_history_of_the_school_privatization_ movement>.

BRAVERMAN, Harry. Labor and monopoly capital. New York: Monthly Review Press, 1998. p. 59-95.

BUCKLY, Jack; SCHNEIDER, Mark. Charter schools: hope or hype. Princeton: Princeton University Press, 2007.

CALKINS, Andrew et al. The turnaround challenge: why America's best opportunity to dramatically improve student achievement lies in our worst-performing schools. Boston, MA: Gates Foundation; Mass Insight Education and Research Institute, 2007. Disponível em: <http://www. massinsight.org/publications/turnaround/51/file/1/pubs/2010/04/15/ TheTurnaroundChallenge_MainReport.pdf>.

CALLAHAN, Raymond E. Education and the cult of efficiency. Chicago: University of Chicago Press, 1962. p. 54-79.

CEP. Center for Educational Policy. New report finds nearly 38\% of U.S. schools do not make ddequately yearly progress under NCLB. Whashington, DC, 28 apr. 2011. Diponível em: <http:/cep-dc.org>. 
CHARTER schools: big experiment. Washington Post, Washington, DC, 9 jun. 2008.

CHILDREN with disabilities fFace discrimination in New Orleans schools. Southern Poverty Law Center, Montgomery, AL, 28 jul. 2010. Disponível em: $<$ http://www.splcenter.org/get-informed/news/splc-complaint-children-withdisabilities-face-discrimination-in-new-orleans-schoo>.

CHILDREN'S DEFENSE FUND. State of America's children: 2010. Washington, DC, 2010. Disponível em: <http://childrensdefense.org>. CODY, Anthony. California governor puts the testing juggernaut on ice. Education Week Teacher, Bethesda, MA, 18 may. 2011. Disponível em: $<$ http://blogs.edweek.org>.

COLEMAN. James Samuel et al.Equality of Educational Opportunity. Washington, DC: U.S. Office of Education, 1966. $1 \mathrm{v}$.

DESPITE long hours and low pay, teachers love their profession. Wisconsin Education Association Council (WEAC), Madinson, WI, 28 agu. 2003. Disponível em: <http://weac.org>. Acesso em: 30 maio 2011.

DEWEY, John. Democracy and Education. New York: The Free Press, 1916.

DU BOFF, Richard. Accumulation and power. New York: M.E. Sharpe, 1989. p. 57-59.

DUNCAN, Arne. A conversation with Arne Duncan, U.S. secretary of education. Council on Foreign Relations, New York, 19 oct. 2010. Disponível: $<$ http://www.cfr.org/education/conversation-arne-duncan-us-secretaryeducation/p23187>.

EDWARDS, Richard. Contested Terrain. New York: Basic Books, 1979. p. 44.

EINSTEIN, Albert. Why Socialism? Monthly Review, v. 1, n. 1, may. 1949.

FISKE, Edward B. Smart Schools, Smart Kids. New York: Simon and Schuster, 1991.

FORERO, Juan. Firms open alternatives to weak Brazilian schools. Washington Post, Washington, 21 april 2011.

FOSTER, John Bellamy; MAGDOFF, Fred. The great financial crisis. New York: Monthly Press, 2009. 
FREIRE, Paulo. The Pedagogy of the oppressed. New York: Seabury Press, 1970.

FRIEDMAN, Milton. Capitalism and freedom. Chicago: University of Chicago Press, 1962.

GARDNER, David P. et al. A Nation at Risk: the imperativefor educational reform. Washington, DC: National Commission on Excellence in Education, abr. 1983. 73 p. Disponível em: <http://teachertenure.procon.org/ sourcefiles/a-nation-at-risk-tenure-april-1983.pdf>.

GLOBAL Education Market. Apollo Global. Chicago, 2007- . Disponível em: <http://apolloglobal.us>. Acesso em: 15 maio 2011.

GOULD, Stephen Jay. The mismeasure of man. New York: W.W. Norton, 1996.

GORELICK, Sherry. Undermining hierarchy: problems of schooling in capitalist America. Monthly Review, New York, v. 29, n. 5, p. 20-36, out. 1977.

GRASS-roots school advocates backed by Gates. New York Times, New York, 22 may. 2001.

HAIMSON, Leonie. A parent guide to the broad foundation's training programs and education policies. Parents Across America, 19 apr. 2011. Disponível em: <http://parentsacrossamerica.org>.

HASS, Nancy. Scholarly Investments. New York Times, New York, 6 dec. 2009.

HOLLAND, Robert. How to build a better teacher. Policy Review, Stanford, CA, n. 106, 1 apr. 2001. Disponível em: <http://hoover.org>.

HOW to tell if your school district is infected by the Broad Virus.

Seattle Education, Seatle, 19 apr. 2011. Disponível em: <http:// parentsacrossamerica.org>.

HU, Winnie; GEBELOFF, Robert. Growth in Education Spending Slowed in 2009. New York Times, New York, 25 may 2011.

HUNGERFORD, Thomas L.; WASSMER, Robert W. K-12 Education and the U.S. Economy: its impact on economic development, earnings, and 
housing values. New York: NEA Research Working Paper, april 2004.

INDIANAPOLIS teachers advocate for immenent layoffs to be based on effectiveness. Teach Plus, Boston, MA, 10 feb. 2011. Disponível em: <http:// www.teachplus.org/page/news-6/news/indianapolis-teachers-advocate-forimminent-layoffs-to-be-based-on-effectiveness-40.html>.

ISIDORE, Chris. Where jobs are booming. CNN Money, Chicago, 16 may 2011. Disponível em: <http://money.cnn.com/2011/05/16/news/economy/ industries_job_gains/index.htm $>$.

KARIER, Clarence J. Testing for order and control in the corporate liberal state. Education Theory, n. 22, spring 1972.

KARP, Stan. NCLB's selective version of equality. In: MEIER, Deborah et al. Many children left behind. Boston: Beacon Press, 2004.p. 63-64.

KLEIN, Naomi. The shock doctrine. New York: Metropolitan Books, 2007.

KOHN, Alfie. What passes for school reform: 'value-added' teacher evaluation and other absurdities. The huffington post, 9 set. 2010. Disponível em: <http://www.huffingtonpost.com/alfie-kohn/what-passes-for-schoolre_b_710696.html>.

KOZOL, Jonathan., The Shame of the Nation. New York: Crown Publishers, 2005.

LEWIS, Karen; POTTER, Jackson. A cauldron of opposition in duncan's hometown: rank and file teachers score a huge victory. An Interview with Karen Lewis and Jackson Potter. Rethinking Schools, n. 25, n. 1, p. 12-17, fall 2010.

MARX, Karl. Early Writings. London: Penguin, 1974.

Capital. London: Penguin, $1976.1 \mathrm{v}$.

MATHIS, William. No child left behind: costs and benefits. Phi Delta Kappan, v. 84, n. 9, may 2003.

MEIER, Deborah. In schools we trust. Boston: Beacon Press, 2002.

. Looking at the truth without flinching. Deborah Meier's Blog on Education, 3 may 2011. Disponível em: <http://deborahmeier.blogspot.com. br/2011/05/looking-at-truth-without-flinching.html>. 
MERCER, Alice. California teachers declare a state of emergency. Labor Notes, Detroit, 19 may. 2011. Disponível em: <http://www.labornotes. org/2011/05/california-teachers-declare-state-emergency>.

MÉSZÁROS, István. Beyond Capital. New York: Monthly Review Press, 1995. p. 142-147.

The challenge and burden of historical time. New York: Monthly

Review Press, 2008.

MINER, Barbara. Ultimate superpower: supersized dollars drive "Waiting for Superman" Agenda. Not waiting for Superman, 20 oct. 2010. Dsponível em: <http://www.notwaitingforsuperman.org/Articles/20101020MinerUltimateSuperpower>.

MIRON, Gary; APPLEGATE, Brooks. Teacher Attrition in Charter Schools. East Lansing, MI: The Great Lakes Center for Education Research \& Practice, may. 2007. Disponível em: <http://greatlakescenter.org/docs/ Research/Miron_Attrition.pdf>.

MIRON, Gary et al. Schools without diversity: education management organizations, charter schools, and the demographic stratification of the American school system. Boulder, CO: Education and the Public Interest Center \& Education Policy Research Unit, feb. 2010. Disponível em: $<$ http://nepc.colorado.edu/files/EMO-Seg.pdf>.

MOCK, Brentin. The myth that charter schools have saved New Orleans. The Root, Washington, DC, 29 aug. 2010. Disponível em: < http://www. theroot.com/views/myth-charter-schools-have-saved-new-orleans>.

NEA. National Educational Association. Status of the American Public School Teacher, 2005-2006. Washington, DC, mar. 2010. Diponível em:< http:// nea.org>

OHANIAN, Susan. 'Race to the top' and the Bill Gates connection. Extra!, New York, sep. 2010. Disponível em: < http://fair.org/extra-online-articles/ race-to-the-top-and-the-bill-gates-connection/>.

OUR approach to investing: venture philanthropy. The Broad Foundation, 2011-. Disponível em: <http://broadeducation.org>. Acesso em: 17 may 2011.

PLANK, David. Charter schools and private profits. The School 
Superintendents Association, Alexandria, VI, may 2000. Disponível em: <http://www.aasa.org/SchoolAdministratorArticle.aspx?id=14510>.

RAVITCH, Diane. Left Back. New York: Simon Schuster, 2000.

. The death and life of the great American school system. New York: Basic Books, 2010.

RICHARDS, Erin. Activist will lead milwaukee teachers' Education Association. Journal Sentinel, 22 may 2011. Disponível em: <http://www. jsonline.com/news/education/122426284.html>.

ROBERT Bobb, broad Superintendent Class of 2005. The Broad Report, 9 jul. 2010. Disponível em: < http://thebroadreport.blogspot.com. br/2010/07/robert-bobb-broad-superintendents.html>.

ROTHSTEIN, Richard. Class and schools: using social, economic, and educational reform to close the black-white ahievement gap. Washington, DC: Economic Policy Institute, 2004.

SADOVNIK, Alan R. Waiting for school reform: charter schools as the latest imperfect panacea. Teachers College Record, New York, 17 mar. 2011. Disponível em: <http://www.tcrecord.org/Content.asp?ContentId=16370>.

SCHMIDT, Sharon. Diane Ravitch stirs overflow crowd in CTO lecture. Substance News, Chicago, IL, 13 mar. 2011. Disponível em: <http://www. substancenews.net/articles. php?page $=2105 \&$ section $=$ Article $>$.

SCOTT, Janelle. The politics of venture philanthropy in charter school policy and advocacy. Educational Policy, Arizona, v. 23, n. 1, jan. 2009.

SYMONDS, William C. Prognosis 2000: Education. Bloomberg Business Week, New York, 10 jan. 2000.

SWARTZ, David L. From correspondence to contradiction and change: schooling in capitalist America revisited. Sociological Forum, Wayne, v. 18, n. 1, p. 167-186, mar. 2003.

TAYLOR, Clarence. Dreamers and Fighters: the NYC Teacher Purges. New York, 2009. Disponível em: <http://dreamersandfighters.com>. Acesso em: 24 maio 2011. . Reds at the Blackboard: communism, civil rights, and the New York teachers union. New York: Columbia University Press, 2011. 
TEACHER for America, STEM Washington and Bill Gates. Seattle Education, Seatle, 22 mar. 2011. Disponível em: <http://seattleduc http:// seattleducation2010.wordpress.com/2011/03/22/teach-for-america-stemwashington-and-bill-gates/aton2010.worpress.com>.

THERNSTROM, Abigail; THERNSTROM Stephen. No Excuses: closing the racial gap in learning. New York: Simon and Schuster, 2003.

THINKEQUITY. New Rules, New Schools, New Market. Vienna: K-12 Education; Industry Outlook, 26 may. 2005. Disponível em: <http://www. educationindustry.org/assets/thinkequity-k12-report.pdf>.

UNITED STATES. Department of Education. The condition of education 2010. Washington, DC: National Center for Education Statistics, may 2010.

WEBER, Karl. Waiting for Superman: how we can save America's failing schools. New York: Public Affairs, 2010.

WEIL, Danny. Disaster capitalism: revisiting the charter schooling and privatization of education in New Orleans. The Daily Censored, 16 may. 2010. Disponível em: <http://dailycensored.com>.

WILLIS, Paul E. Learning to Labour. Westmead, Saxon House, 1977. 


\section{Educación y la crisis Education and structural estructural de capital: el crisis of capital: the case of caso de los Estados Unidos the United States}

\section{Resumen}

El presente artículo argumenta que la decadencia de la enseñanza pública es, principalmente, en los Estados Unidos de Norte América, producto de las contradicciones impuestas externamente y que son inherentes a la educación en la sociedad capitalista, profundizadas en nuestros tiempos por las condiciones de estagnación económica, en especial en las economías desarrolladas y también, por los efectos de la propia reforma conservadora. Para tal fin, se presentan los presupuestos de la política educacional y los desdoblamientos y consecuencias para la educación pública - a partir de una perspectiva histórica - en el contexto de la crisis estructural del capital en los Estados Unidos de Norte América. Se explicita que la crisis estructural asociada a una nueva fase del capitalismo: el capital monopolista - financiero se caracteriza por: (1) estagnación económica en las economías capitalistas desarrolladas; (2) un cambio dramático hacia la financierización, esto es, las burbujas especulativas como un medio de expansión económica; y (3) la rápida concentración (y monopolización) del capital en escala global, mostrando así, como una de sus consecuencias, el lento crecimiento endémico para las economías desarrolladas en que las grandes corporaciones que dominan la economía mundial actual son

\section{Abstract}

This article argues that the decadence of public education in the United States is mainly a product of contradictions imposed externally that are inherent to education in capitalist society. They have been aggravated by economic stagnation, particularly in the developed economies, and by the effects of the conservative reform movement. The article presents the suppositions of educational policy and its consequences and effects on public education - based on a historical perspective - in the context of the structural crisis of capital in the United States. It identifies the structural crisis associated to a new phase of capitalism: monopoly financial capital, which is characterized by: (1) economic stagnation in the developed capitalist economies; (2) a dramatic change in direction towards financialization, speculative bubbles as a means of economic expansion; and (3) the rapid concentration (and monopolization) of capital on a global scale. One consequence of the slow growth endemic to the developed economies is that the large corporations that dominate the current global economy are required to seek new markets for investment outside of their traditional areas of operation, which leads to the acquisition and privatization of key elements of state administration. The political counterpart 
obligadas a procurar nuevos mercados para las inversiones fuera de las aéreas tradicionales de actuación, generando así, la privatización y la adquisición de elementos claves en la administración del Estado. La contra partida política del capital monopolista - financiero por lo tanto es, la reestructuración neoliberal, en que el Estado es cada vez más ocupado por los intereses privados. Se presentan diversos autores del área de la economía y con base en Marx, el autor va informando la relación de degradación y desvalorización de la educación pública. Finaliza su análisis indicando la necesidad de una larga revolución para criar, entre otras cuestiones, un nueva educación articulada a la comunidad y desarrollada a partir de las necesidades reales de las personas.

Palabras claves: Crisis estructural. Capital. Educación Pública. Estados Unidos de Norte América.

\section{John Bellamy Foster}

E-mail: jfoster@uoregon.edu

Claúdio Garcia Araújo

E-mail: clamagara@gmail.com of monopoly financial capital is, therefore, the neoliberal restructuring, in which the state is increasingly occupied by private interests. The paper looks at various authors in the field of economics and based on Marx presents the relation of degradation and devaluation of public education. It concludes by indicating the need for a long revolution to create, among other things, a new education linked to the community, and developed with a basis on the real needs of people.

Keywords: Structural Crisis. Capital. Public school education. The United States of America.

Recebido em: 25/9/2012

Versão final recebida em: $10 / 11 / 2012$

Aprovado em: 11/11/2012 